
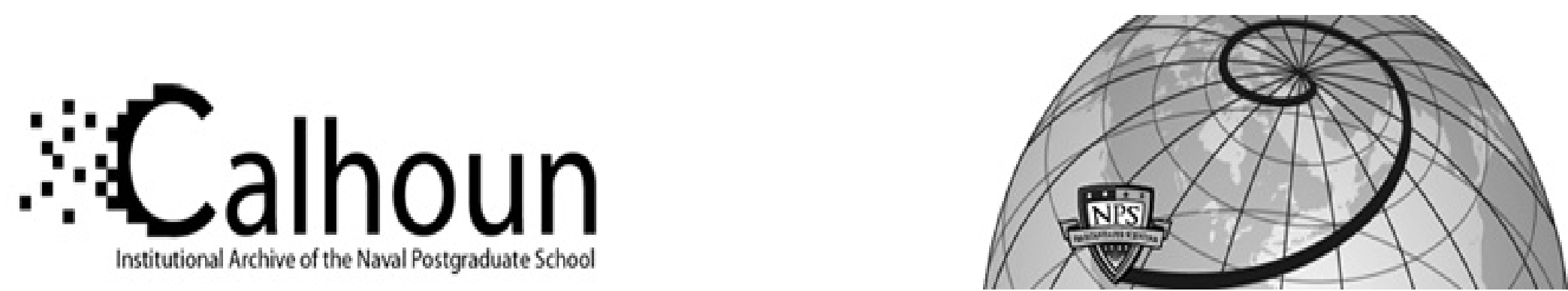

Calhoun: The NPS Institutional Archive DSpace Repository

Drizzle suppression in ship tracks

Ferek, Ronald J.; Garrett, Timothy; Hobbs, Peter V.; Strader, Scott; Johnson, Doug; Taylor, Jonathan; Nielsen, Kurt; Ackerman, Andrew S.; Kogan, Yefim; Liu, Qingfu... American Meteorological Society Journal of the Atmospheric Sciences, v. 57, August 15, 2000, Pp. 2707-2728 https://hdl.handle.net/10945/46780

This publication is a work of the U.S. Government as defined in Title 17, United States Code, Section 101. Copyright protection is not available for this work in the United States.

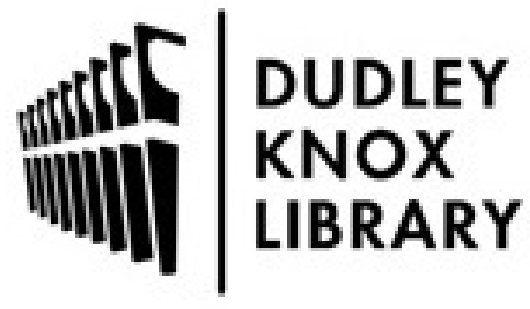

http://www.nps.edu/library
Calhoun is the Naval Postgraduate School's public access digital repository for research materials and institutional publications created by the NPS community. Calhoun is named for Professor of Mathematics Guy K. Calhoun, NPS's first appointed -- and published -- scholarly author.

Dudley Knox Library / Naval Postgraduate School 411 Dyer Road / 1 University Circle Monterey, California USA 93943 


\title{
Drizzle Suppression in Ship Tracks
}

\author{
Ronald J. Ferek,*,++ Timothy Garrett,* Peter V. Hobbs,* Scott Strader,* Doug Johnson, ${ }^{+}$ \\ Jonathan P. TaYlor, + Kurt Nielsen, \# Andrew S. AcKerman, @ Yefim Kogan, \& \\ Qingfu Liu, \& Bruce A. Albrecht, ${ }^{* *}, \# \#$ AND David BABB** \\ * Atmospheric Sciences Department, University of Washington, Seattle, Washington \\ ${ }^{+}$Meteorological Research Flight, The Met. Office, Farnborough, Hampshire, United Kingdom \\ \# Department of Meteorology, Naval Postgraduate School, Monterey, California \\ @ NASA Ames Research Center, Moffett Field, California \\ \& Cooperative Institute for Mesoscale Meteorological Studies, University of Oklahoma, Norman, Oklahoma \\ ** Department of Meteorology, The Pennsylvania State University, University Park, Pennsylvania
}

(Manuscript received 15 October 1996, in final form 3 December 1997)

\section{ABSTRACT}

\begin{abstract}
Although drizzle was a relatively infrequent occurrence during the Monterey Area Ship Track study, diverse measurements from several sources produced data signals consistent with a reduction in drizzle drops in stratus clouds affected by ship effluents. Concurrent increases in liquid water in the cloud droplet size range, due to redistribution from the drizzle mode, were not always observed, possibly because of the relatively small and often negligible amounts of water in the drizzle mode. Significant changes in cloud droplet size distribution, as well as reductions in drizzle flux and concentrations of drops $>50-\mu \mathrm{m}$ radius, were observed in ship tracks when drizzle was more uniformly present in the ambient cloud.

Radiometric measurements showed that increased droplet concentrations in ship tracks, which resulted in reduced droplet sizes, can significantly alter the liquid water path. Radar observations indicated that the reduced reflectivities of ship tracks compared with ambient clouds may be due to reductions in the concentrations of larger drops and/or reductions in the sizes of these drops. Two independent modeling studies showed decreases in drizzle in ship tracks due to the presence of smaller cloud droplets that reduced the efficiency of drop growth by collisions.
\end{abstract}

\section{Introduction}

One of the most important goals of the Monterey Area Ship Track (MAST) study was to investigate the microphysical changes in stratus clouds and drizzle within ship tracks. The hypothesis to be tested can be summarized as follows: cloud condensation nuclei (CCN) in the plume of emissions from a ship increase cloud droplet concentrations and decrease cloud droplet radii in a ship track. If drizzle-size drops are present in the ambient cloud, the ship track will have fewer droplets in the collision-coalescence size range and consequently fewer drizzle-size drops. Since drizzle is a sink for cloud liquid water, suppression of drizzle should lead to an

++ Current affiliation: Office of Naval Research, Washington, D.C.

\#\# Current affiliation: Department of Meteorology and Physical Oceanography, University of Miami, Coral Gables, Florida.

Corresponding author address: Dr. Peter V. Hobbs, Department of Atmospheric Sciences, University of Washington, Seattle, WA $98195-$ 1640.

E-mail: phobbs@atmos.washington.edu increase in liquid water content in the cloud droplet size range in the ship track.

If the above processes occur, possible implications include the following: 1) Polluted marine stratus clouds may precipitate less than unpolluted clouds. 2) Suppression of drizzle by pollution may increase the amount and stability of stratus clouds and increase their cooling effect on climate. 3) Redistribution of drizzle liquid water to smaller droplets may increase the liquid water path in stratus clouds and consequently alter their radiative properties.

Droplets with radii up to about $10 \mu \mathrm{m}$ may grow in clouds by condensation from the vapor phase. Thereafter, any further growth occurs by the collision and coalescence of droplets (e.g., Wallace and Hobbs 1977). Relatively large droplets are more likely to form in clouds with low CCN concentrations (Squires 1958; Hindman et al. 1977a; Albrecht 1989). Gerber (1996) investigated the occurrence of drizzle as a function of effective droplet radius for a variety of marine stratus clouds and described a so-called drizzle threshold with an effective radius of about $15 \mu \mathrm{m}$. Stratus clouds with effective radii below this threshold generally did not produce significant drizzle. 
Documentation of specific sources of pollution changing cloud microstructures and precipitation is sparse and, at face value, somewhat contradictory. Warner (1968) attributed reductions in rainfall associated with smoke from sugarcane fires to large numbers of CCN from these fires, which produce increases in droplet concentrations and decreases in average droplet sizes (Warner and Twomey 1967). Eagan et al. (1974a) found that forest fires produce $\sim 6 \times 10^{10} \mathrm{CCN}$ (at $0.5 \%$ supersaturation) per gram of wood consumed, and that these particles can increase cloud droplet concentrations and decrease cloud droplet sizes. Hobbs et al. (1970), Eagan et al. (1974b), and Hindman et al. (1977a) showed that large paper mills are prolific sources of $\mathrm{CCN}$. In this case, however, clouds affected by such plumes have higher droplet concentrations and broader droplet size spectra and appear to precipitate more readily (Hobbs et al. 1970). This could be due to paper mills emitting both large and giant CCN, which increase the concentrations of both small and large droplets and thereby enhance the growth of raindrops by the collision-coalescence mechanism. However, Hindman et al. (1977b) concluded from modeling studies that this effect alone cannot explain increases in rainfall downwind of paper mills, but it might do so when combined with the effects of heat and moisture outputs from paper mills. While conducting in situ measurements in two features believed to be ship tracks off southern California, Radke et al. (1989) and King et al. (1993) observed an increase in cloud liquid water and a decrease in drizzle-size drops in the tracks. In two ship tracks measured off the coast of Washington a reduction in drizzle drops was observed, but no associated increase in cloud liquid water (Ferek et al. 1998).

The experimental approach in MAST involved the use of two airborne platforms and one research vessel to investigate the phenomenon of ship tracks. The aircraft were equipped with a variety instruments to collect in situ cloud microphysical and cloud radiative measurements. The research vessel equipment included a radar suitable for measurement of drizzle, a ceilometer for measurement of cloud base, and a microwave radiometer for the measurement of cloud liquid water path. The data collected were compared to two independent numerical models to investigate the microphysical processes in stratus clouds affected by ship tracks.

\section{Platforms and instrumentation}

\section{a. The University of Washington's (UW's) Convair C-131A aircraft}

A description of the instrumentation aboard the Convair C-131A has been given by Hobbs et al. (1991). The distributions of droplets between 1- and $350-\mu \mathrm{m}$ radius are measured with Particle Measuring Systems (PMS) FSSP-100 (Forward Scattering Spectrometer
Probe) and OAP-2D-C (Optical Array Probe) cloud probes. A correction for coincidence and dead time losses (Baumgardner 1982; Mossop 1983) was applied to all measurements with the FSSP-100. The PMS OAP2D-C records images of cloud droplets between 25- and $350-\mu \mathrm{m}$ radius as they pass through a $12.5-\mu \mathrm{m}$-resolution diode array. A correction algorithm (Baumgardner 1987) was applied to the data that (a) corrects for undersizing of drops due to digitization errors at airspeeds greater than $\sim 50 \mathrm{~m} \mathrm{~s}^{-1}$, by shifting the counts in each channel up by one channel $(12.5 \mu \mathrm{m})$ radius, and (b) adjusts the depth of field in each channel to allow for the electronic response time of the probe. Cloud liquid water content (LWC) measurements were obtained using the Gerber Scientific PVM-100A liquid water probe, and by integrating FSSP-100 volume distributions between 1 - and $23-\mu \mathrm{m}$ radius. The PVM$100 \mathrm{~A}$ responds linearly to LWC over the droplet radius range 2-22 $\mu \mathrm{m}$; however, for droplets less than $\sim 1 \mu \mathrm{m}$ and more than $\sim 35 \mu \mathrm{m}$ in radius, it underestimates LWC by more than 50\% (Gerber et al. 1994). However, since the PVM-100A is partially sensitive to droplets greater than the upper limit of the FSSP, it was slightly more sensitive at detecting LWC increases associated with the suppression of drizzle. For the range of LWC encountered in maritime stratus cloud layers in MAST, the agreement between the integrated FSSP-100 LWC and the PVM-100A LWC was generally better than $20 \%$. The PVM-100A has the advantage of faster response (10 vs $4 \mathrm{~Hz}$ for the FSSP-100). The drizzle LWC was derived by integrating OAP-2D-C volume distributions between $25-$ and $350-\mu \mathrm{m}$ radius.

\section{b. The Met. Office's Lockheed C-130}

A brief list of some of the instruments aboard the U.K. Met. Office (UKMO) Lockheed C-130 relevant to the drizzle study is given here. A more complete description is given by Taylor et al. (2000). A complete description of the standard meteorological instrumentation aboard the C-130 is given by Nicholls (1978); the cloud physics instrumentation, by Martin et al. (1994) and Brown (1993); and the radiation instrumentation, by Kilsby et al. (1992) and Saunders et al. (1992).

Eppley pyranometers with red (transmit $0.7-3.0 \mu \mathrm{m}$ ) and clear (transmit $0.3-3.0 \mu \mathrm{m}$ ) domes, two on the top of the aircraft and two on the underside, were used to measure broadband hemispherical irradiances in the near-infrared and total solar spectrum from which visible irradiances $(0.3-0.7 \mu \mathrm{m})$ were inferred. The Microwave Airborne Radiometer (MAR) Scanning System (MARSS) was used to measure emission at 89 and 157 $\mathrm{GHz}$ and can be used to retrieve cloud liquid water path (English 1995). A Multi-Channel Radiometer (MCR, Rawlins and Foot 1990) was used to measure radiances in 14 narrow spectral bands between 0.55 and $12 \mu \mathrm{m}$. Cloud optical depth $(\tau)$ and cloud droplet effective radius $\left(r_{e}\right)$ can be retrieved using MCR measurements of 
the reflectance at two wavelengths in the visible or nearinfrared. In addition to the radiation instrumentation, cloud microphysical data were obtained from PMS probes (FSSP, 2D-C), similar to those aboard the UW C-131A, and a Johnson-Williams liquid water probe.

Though qualitative conclusions can be drawn from the plots of drop size distributions derived by the UKMO's C-130 and the UW's C-131A, the two groups use different methods for processing the data. The UW C-131A is equipped with a PMS OAP-2D-C, and data from this probe are processed with Baumgardner's (1987) algorithm [see (a) above]. The C-130 is equipped with a PMS OAP-2D2-C, but the Baumgardner algorithm is not applied to the data gathered by the C-130. During MAST, the UKMO typically derived higher drizzle drop concentrations than the UW. The most likely explanation for this difference is the depth of field correction applied by the UW. Due to the increase in sample volume with channel number for the first six channels of the PMS OAP, shifting a given number of counts in one channel up to the next higher channel results in lower drop concentrations (same number of particles, but a larger sample volume). The overall effect is that, for a given cloud, the total concentrations of drops derived from a PMS OAP should be lower using the UW processing algorithm than that derived by the UKMO.

\section{c. $R / V$ Glorita}

A suite of remote sensing systems to study cloud properties was operated by The Pennsylvania State University aboard the research vessel R/V Glorita. The instrumentation used for studying drizzle included a 94$\mathrm{GHz}$ radar, a microwave radiometer, and a laser ceilometer. Since radar reflectivity depends on the radius of the drop scatterers raised to the sixth power, the radar returns from the $94-\mathrm{GHz}$ radar are very sensitive to drizzle. The 94-GHz radar is described and evaluated by Clothiaux et al. (1995). This bistatic system operates at a peak power of $1.4 \mathrm{~kW}$ with a beam width of $0.25^{\circ}$ and can detect reflectivities as low as $-50 \mathrm{dBz}$ at $1 \mathrm{~km}$. The signal processors that operate with this system are nominally set to sample at intervals from 1 to $5 \mathrm{~s}$. The microwave radiometer was used to estimate integrated liquid and water vapor path using observations of sky temperatures at 22.2, 24.1, and $31.7 \mathrm{GHz}$. Han and Thomson (1994) describe the microwave radiometer and the retrieval techniques that are applied to the raw data. Data were saved at 5-s intervals during MAST. The laser ceilometer (Vaisala model CT 12K), which was used to estimate cloud-base heights from the R/V Glorita, has been used extensively for studies of marine stratocumulus (e.g., Albrecht et al. 1990). This instrument makes use of a GaAS laser diode operating at a wavelength of $0.904 \mu \mathrm{m}$; it provided cloud-base estimates every $30 \mathrm{~s}$ with $15-\mathrm{m}$ resolution.

\section{Ages of air parcels}

The age of an air parcel along any point of penetration by the aircraft was determined using an advection analysis. Ship positions, courses, and speeds were determined from the positions of the ship track heads on successive Advanced Very High Resolution Radiometer satellite images. Boundary layer winds were estimated from the $1.25^{\circ}$ by $1.25^{\circ} \mathrm{NGM} 0000$ UTC gridded wind field. From these inputs a 2D horizontal field of emission times for plume parcels was derived. The time and position of an aircraft penetration of a ship track could then be superimposed on the emission time field. The difference between the aircraft penetration time and the emission time yields the age of the plume/track parcel.

\section{Results}

Out of the approximately 30 ship tracks measured off the California coast during MAST, only seven occurred in clouds that had measurable drizzle modes (i.e., effective radii at, or above, the "drizzle threshold"). Two cases were observed from the UW C-131A (in ship tracks produced by the Star Livorno and Moku Pahu), and measurements were obtained in approximately the middle of these clouds. Four cases (involving five ships, the Hundai Duke, Sanko Peace, USS Safeguard, Evergreen Evergenius, and Hanjin Barcelona) were observed from the UKMO C-130, and measurements were obtained below, and in, these clouds. In at least one case, features that could be attributed to changes in drizzle properties associated with a ship track were observed with the $94-\mathrm{GHz}$ radar aboard the R/V Glorita. In this section we describe first the results of observations during MAST that are relevant to the ship track drizzle hypothesis. We then describe two modeling efforts to examine various aspects of the effect of ship tracks on drizzle.

\section{a. Moku Pahu (12 June 1994)}

The ship track produced by this ship was encountered by the UW C-131A about $100 \mathrm{~km}$ west of Santa Cruz, California, and extended west for another $100 \mathrm{~km}$. Ambient clouds in the vicinity were characterized by rather low droplet concentrations of about $30 \mathrm{~cm}^{-3}$, LWC ranging from 0.1 to $0.2 \mathrm{~g} \mathrm{~m}^{-3}$, and an effective droplet radius of about $13 \mu \mathrm{m}$. Drizzle drops were detected sporadically. The stratus cloud layer was about $250 \mathrm{~m}$ thick with its base near $150 \mathrm{~m}$ above sea level (ASL). Six penetrations of the ship track were made by the $\mathrm{C}-131 \mathrm{~A}$ at times ranging from 10 to $32 \mathrm{~min}$ after emission. For the track penetration at $26 \mathrm{~min}$ after emission, Fig. 1a shows the size distributions from the FSSP and 2D probes in both the ship track and surrounding ambient cloud. Figure 1b shows the time series of total LWC from the 2D plus FSSP probes and from the 2D probe alone. Examination of similar plots for each of 

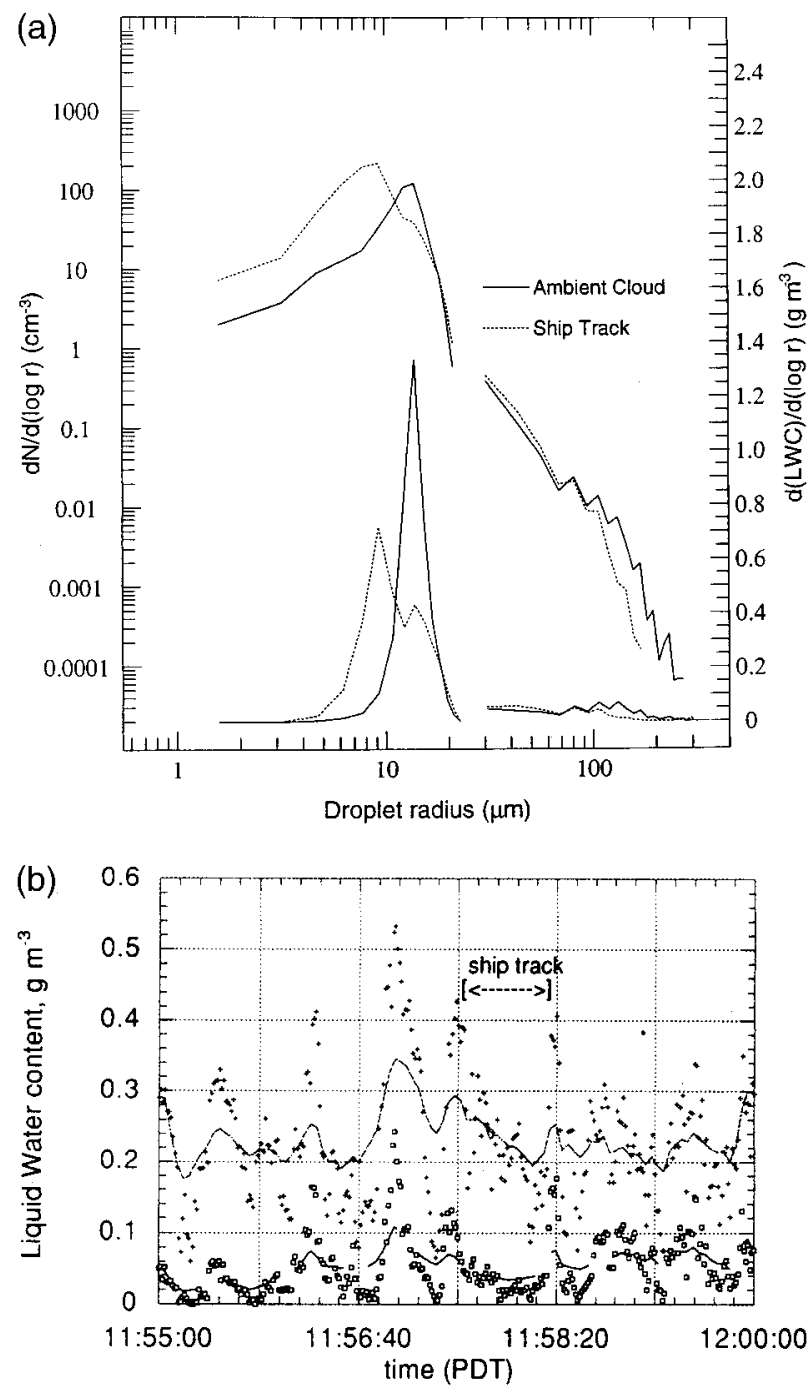

FIG. 1. (a) Cloud and drizzle drop size distributions (upper curves) and liquid water concentrations (LWC) (lower curves) for the ambient cloud (solid lines) and the ship track (dashed lines) measured on 12 Jun 1994 downwind of the Moku Pahu. (b) Time series of 1-s averages and a smoothed curve fit of total LWC (FSSP and 2D probes) (crosses, solid line) and LWC from the 2D probe (open squares, dashed line) for the same track penetration.

the other five penetrations of this ship track showed that in only one case was there a statistically significant increase of cloud LWC compared to the ambient cloud on either side of the track, and ambient variability appeared to account for this rather than a redistribution of liquid water from the drizzle mode. Two of the penetrations showed a slight decrease in the LWC from the OAP-2D-C probe; two showed a slight increase; and one had no drizzle mode.

Expressing the total LWC as the sum of cloud and drizzle LWC (Fig. 1b) illustrates that most of the variability in total LWC is due to the variability of the drizzle LWC rather than the cloud LWC, which is relatively constant. Given the high variability in the LWC from the OAP-2D-C probe, which is generally only about $20 \%$ or less of the total LWC, it is not surprising that statistically significant shifts of LWC between the modes are difficult to detect and that no statistically significant changes in the size distribution of drops derived from the OAP-2D-C probe could be attributed to the ship. The amounts of LWC in the drizzle mode and the drizzle rate were low, so that even if all of the LWC measured by the OAP-2D-C probe were redistributed to smaller sizes, the increase in LWC of the cloud droplets would not be apparent above the natural variability in the cloud LWC. The ages of the parcels sampled ranged from only 10 to $32 \mathrm{~min}$, so that insufficient time may have elapsed to mix and equilibrate the drizzle and cloud modes within the ship track. Overall, this was an inconclusive case for testing the hypothesis that ship tracks contain more liquid water than adjacent clouds.

\section{b. Star Livorno (29 June 1994)}

The ship track produced by this ship was first encountered by the UW C-131A about $200 \mathrm{~km}$ west of Monterey, California. Ambient clouds in the region were characterized by a droplet concentration of about $50 \mathrm{~cm}^{-3}$, an LWC of $0.1-0.3 \mathrm{~g} \mathrm{~m}^{-3}$, and effective radii around $12 \mu \mathrm{m}$. Cloud base was at about $435 \mathrm{~m}$ and cloud top at $630 \mathrm{~m} \mathrm{ASL}$. Although drizzle drops were variable in concentration, they were observed consistently over most of the vicinity of this ship track. Seven penetrations of the track were made by the C-131A at times ranging from 42 to $81 \mathrm{~min}$ after emission. A reduction of drizzle flux was observed for most penetrations of this track. Figure 2a shows the cloud and drizzle drop size distributions measured in the ship track and ambient cloud for the track penetration that showed the largest reduction in drizzle (80 min after emission). Figure $2 \mathrm{~b}$ shows the corresponding time series of total LWC from the FSSP-100 and OAP-2D-C probes and LWC from the OAP-2D-C probe. Figure 2c shows similar quantities derived from the PVM-100A probe. The slight increase in cloud LWC in the ship track is more apparent in the Gerber probe data, probably due to its greater sensitivity to drops in the $23-35-\mu$ m-radius range, which fall in the region of reduced sensitivity near the upper limit of the FSSP and the lower limit of the OAP-2D-C probe. Figure 3 shows the total number concentration of drizzle drops measured by the OAP2D-C probe in the ship track at 1302 (13:01:30-13:02: 34) Pacific daylight time (PDT). A decrease in the concentration of drizzle drops in the ship track is evident.

Perhaps a more significant measure of the effect of drizzle suppression is indicated by comparison of the drizzle fluxes calculated for each penetration of the two tracks described above and in the ambient cloud on either side of these tracks (Table 1). Given the uncertainty in the calculated drizzle fluxes (approximately $0.25 \mathrm{~mm} \mathrm{day}^{-1}$ ) only two of the six transects of the Moku Pahu ship track showed a reduction in drizzle, 


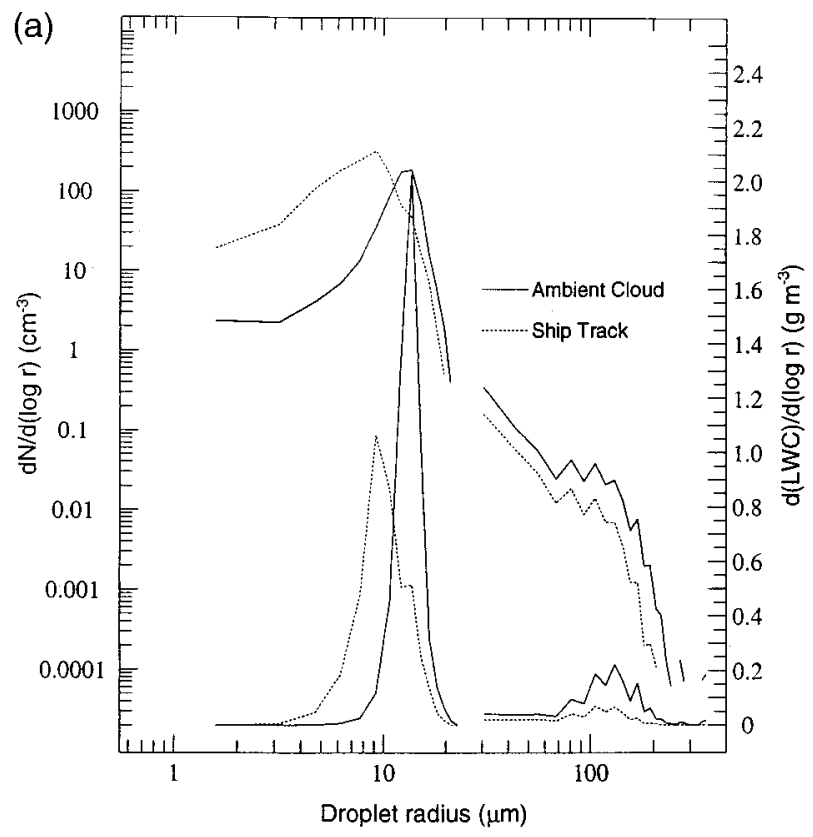

Fig. 2. (a) As for Fig. 1a except for 29 Jun 1994 downwind of the Star Livorno. (b) As for Fig. 1b except for 29 Jun 1994 downwind of the Star Livorno. (c) As for Fig. 1b except for 29 Jun 1994 downwind of Star Livorno and for total LWC calculated from the PVM$100 \mathrm{~A}$ and OAP-2D-C probes.
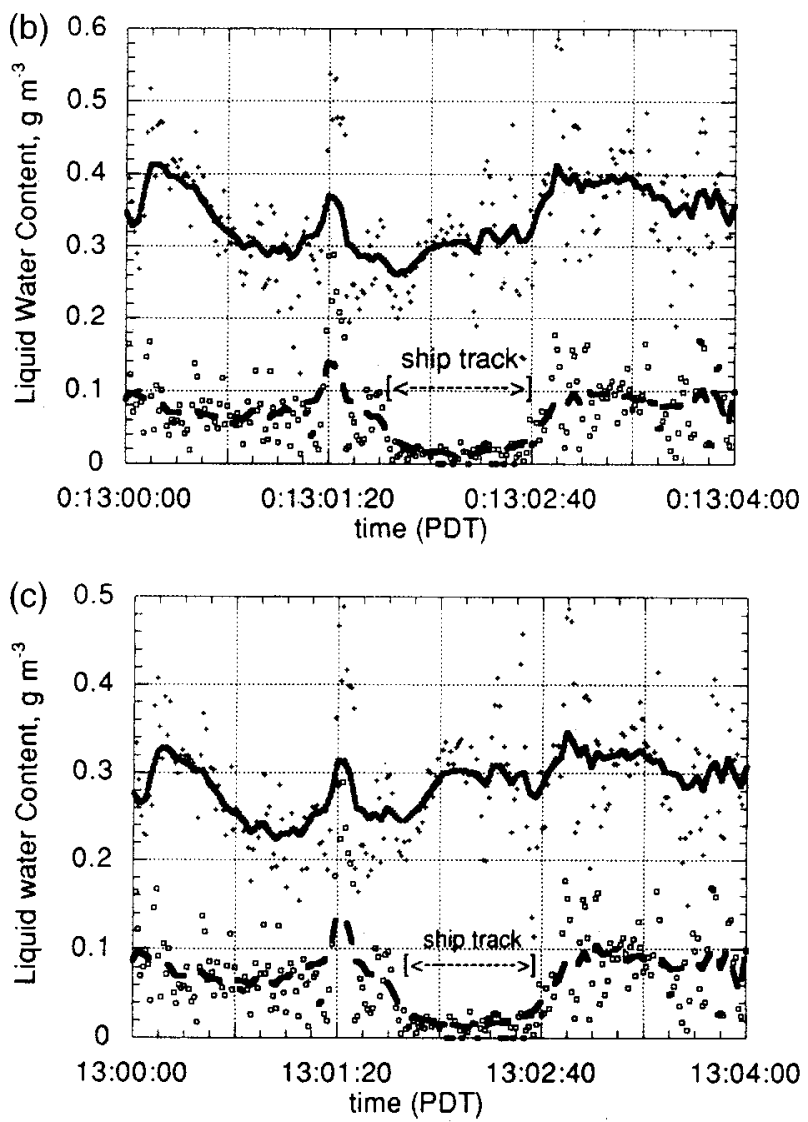

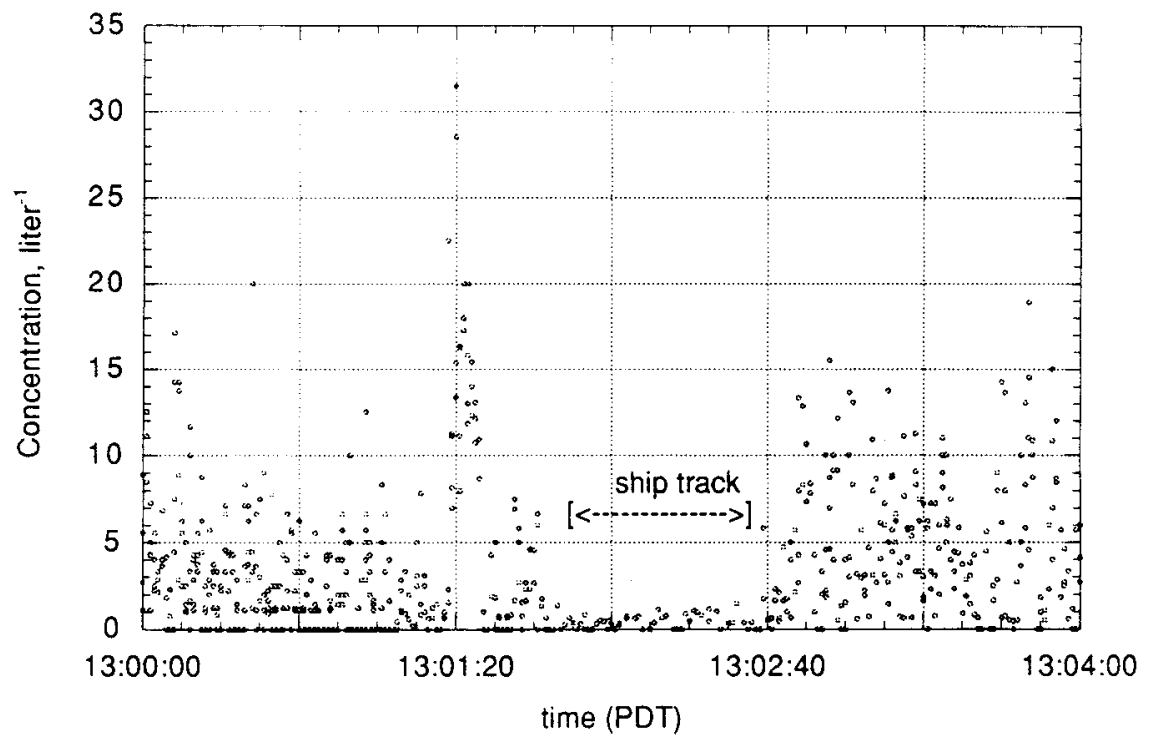

FIG. 3. Time series of total number concentration of drizzle drops measured by the $2 \mathrm{D}$ probe for the same ship track penetration shown in Fig. 2. 
TABLE 1. Ship track age and drizzle rates (calculated from PMS OAP-2D-C probe) for UW C-131A penetrations of the ship track and for ambient cloud on either side of the ship track. The errors in the calculated values are the standard errors of the mean.

\begin{tabular}{cccc}
\hline \hline \multirow{2}{*}{ Ship } & \multirow{2}{*}{$\begin{array}{c}\text { Age of ship } \\
\text { track (min) }\end{array}$} & \multicolumn{2}{c}{ Drizzle rate $\left(\mathrm{mm} \mathrm{day}^{-1}\right)$} \\
\cline { 3 - 4 } Moku Pahu & 10 & $0.6 \pm 0.09$ & $0.3 \pm 0.02$ \\
& 14 & $0.2 \pm 0.05$ & $0.7 \pm 0.20$ \\
& 18 & $0.1 \pm 0.01$ & $0.0 \pm 0.05$ \\
& 22 & $0.1 \pm 0.01$ & $0.0 \pm 0.01$ \\
& 26 & $1.3 \pm 0.20$ & $1.0 \pm 0.09$ \\
& 32 & $1.9 \pm 0.08$ & $2.8 \pm 0.29$ \\
Star Livorno & 42 & $2.5 \pm 0.36$ & $1.5 \pm 0.38$ \\
& 52 & $0.8 \pm 0.10$ & $0.5 \pm 0.17$ \\
& 55 & $1.8 \pm 0.26$ & $0.7 \pm 0.10$ \\
& 65 & $2.1 \pm 0.18$ & $0.3 \pm 0.04$ \\
& 75 & $3.0 \pm 0.27$ & $2.5 \pm 0.43$ \\
& 80 & $4.9 \pm 0.31$ & $1.4 \pm 0.17$ \\
& 81 & $1.2 \pm 0.12$ & $0.3 \pm 0.14$ \\
\hline
\end{tabular}

while two showed an increase. Given the small amounts of drizzle present, these differences are within the statistical noise. However, every pass through the Star $\mathrm{Li}$ vorno track showed evidence of drizzle reduction, although the uncertainties overlapped for two of the passes. Figure 4 shows a plot of the reduction in drizzle flux in the Star Livorno track versus the reduction in the number of droplets between 20 - and $40-\mu$ m radius. The drizzle flux is highly correlated with the concentration of droplets with radii between 20 and $40 \mu \mathrm{m}$, which are good collector drops.

\section{c. Hyundai Duke (8 June 1994)}

The UKMO C-130 investigated the plume and cloud track from the Hyundai Duke, a container vessel with a diesel propulsion unit. It was encountered late in the flight at $37.3^{\circ} \mathrm{N}, 125.1^{\circ} \mathrm{W}$, heading on a course of $18^{\circ}$ at $13 \mathrm{~m} \mathrm{~s}^{-1}$. This ship produced a very marked cloud track (Russell et al. 2000), although there were very few other ship tracks apparent in the satellite photographs on that day.

Apart from a narrow, clear region near the coast, most of the sea areas were covered with an extensive sheet of stratocumulus. Near the edge of the cloud sheet, where the Hyundai Duke was encountered, the cloud had a roll structure and the rolls were aligned approximately parallel to the wind. The air mass was clean, with aerosol concentrations in the accumulation mode in the boundary layer of $50 \mathrm{~cm}^{-3}$ or less. The droplet concentrations in the cloud were between 40 and 50 $\mathrm{cm}^{-3}$, and the maximum effective cloud droplet radius was $11 \mu \mathrm{m}$. The peak LWC near cloud top was $0.4 \mathrm{~g}$ $\mathrm{kg}^{-1}$, and patchy drizzle was encountered in the boundary layer throughout the flight. However, the drizzle was very light, and as shown in Table 2, the average precipitation rate measured in the cloud close to the ship track did not exceed $0.2 \mathrm{~mm}$ day $^{-1}$.

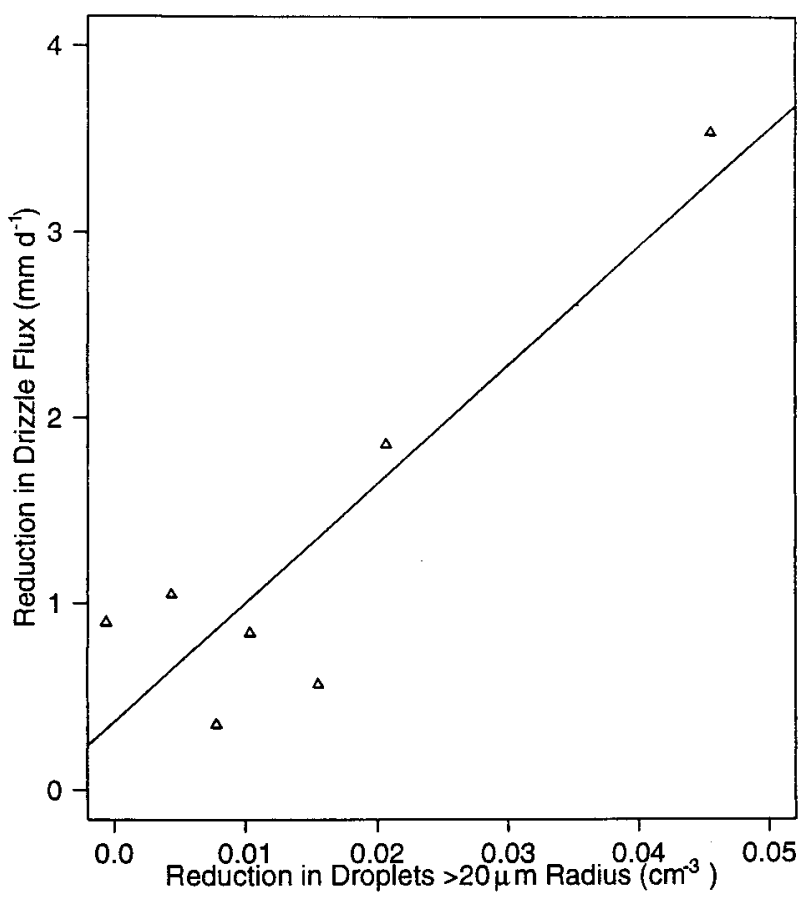

FIG. 4. Reduction in drizzle flux vs reduction in the concentration of droplets $>20 \mu \mathrm{m}$ from measurements made in seven penetrations of the ship track produced by the Star Livorno.

The Hyundai Duke produced a large visible plume. Very close to the ship, peak concentrations of accumulation-mode aerosol of nearly $7000 \mathrm{~cm}^{-3}$ were measured in a few hundred meter wide plume. This was

TABLE 2. Ship track age and drizzle rates (calculated from PMS OAP-2D2-C probe) for UKMO C-130 penetrations of the ship track and for ambient cloud on either side of the ship track. The errors in the calculated values are standard errors of the mean.

\begin{tabular}{lcccc}
\hline \hline \multirow{2}{*}{ Ship } & \multirow{2}{*}{$\begin{array}{c}\text { Run } \\
\text { number }\end{array}$} & $\begin{array}{c}\text { Age } \\
\text { (h) }\end{array}$ & \multicolumn{2}{c}{ Drizzle rate $\left(\mathrm{mm} \mathrm{day}^{-1}\right)$} \\
\cline { 4 - 5 } Hyundai Duke & 7 & 2.42 & $0.18 \pm 0.09$ & $0.06 \pm 0.04$ \\
& 8 & 2.00 & $0.14 \pm 0.09$ & $0.07 \pm 0.02$ \\
Safeguard & 9 & 1.33 & $0.03 \pm 0.02$ & $0.02 \pm 0.01$ \\
& 3.1 & 0.42 & $1.90 \pm 1.20$ & $0.47 \pm 0.34$ \\
& 3.2 & 0.33 & $0.39 \pm 0.56$ & $0.27 \pm 0.28$ \\
& 4.2 & 0.42 & $0.33 \pm 0.35$ & $0.32 \pm 0.32$ \\
Sanko Peace & 5.1 & 2.50 & $0.66 \pm 0.34$ & $0.57 \pm 0.15$ \\
& 10.1 & 1.42 & $1.00 \pm 0.51$ & $0.82 \pm 0.83$ \\
& 10.4 & 1.00 & $2.65 \pm 1.46$ & $1.45 \pm 1.15$ \\
Evergreen & 10.5 & 1.08 & $0.71 \pm 0.79$ & $0.60 \pm 0.26$ \\
Evergenius & 11.1 & 0.83 & $1.40 \pm 0.94$ & $0.54 \pm 0.69$ \\
Hanjin Barcelona & 11.2 & 1.08 & $0.24 \pm 0.25$ & $0.11 \pm 0.09$ \\
& 5.2 & 0.50 & $0.16 \pm 0.06$ & $0.10 \pm 0.03$ \\
& 7.3 & 1.10 & $0.13 \pm 0.06$ & $0.06 \pm 0.03$ \\
& 8.2 & 1.50 & $0.02 \pm 0.02$ & $0.02 \pm 0.01$ \\
& 3.3 & 0.42 & $0.86 \pm 0.34$ & $1.98 \pm 0.68$ \\
& 4.4 & 1.00 & $0.41 \pm 0.46$ & $0.26 \pm 0.25$ \\
& 4.6 & 3.37 & $0.76 \pm 0.22$ & $0.20 \pm 0.13$ \\
& & & &
\end{tabular}




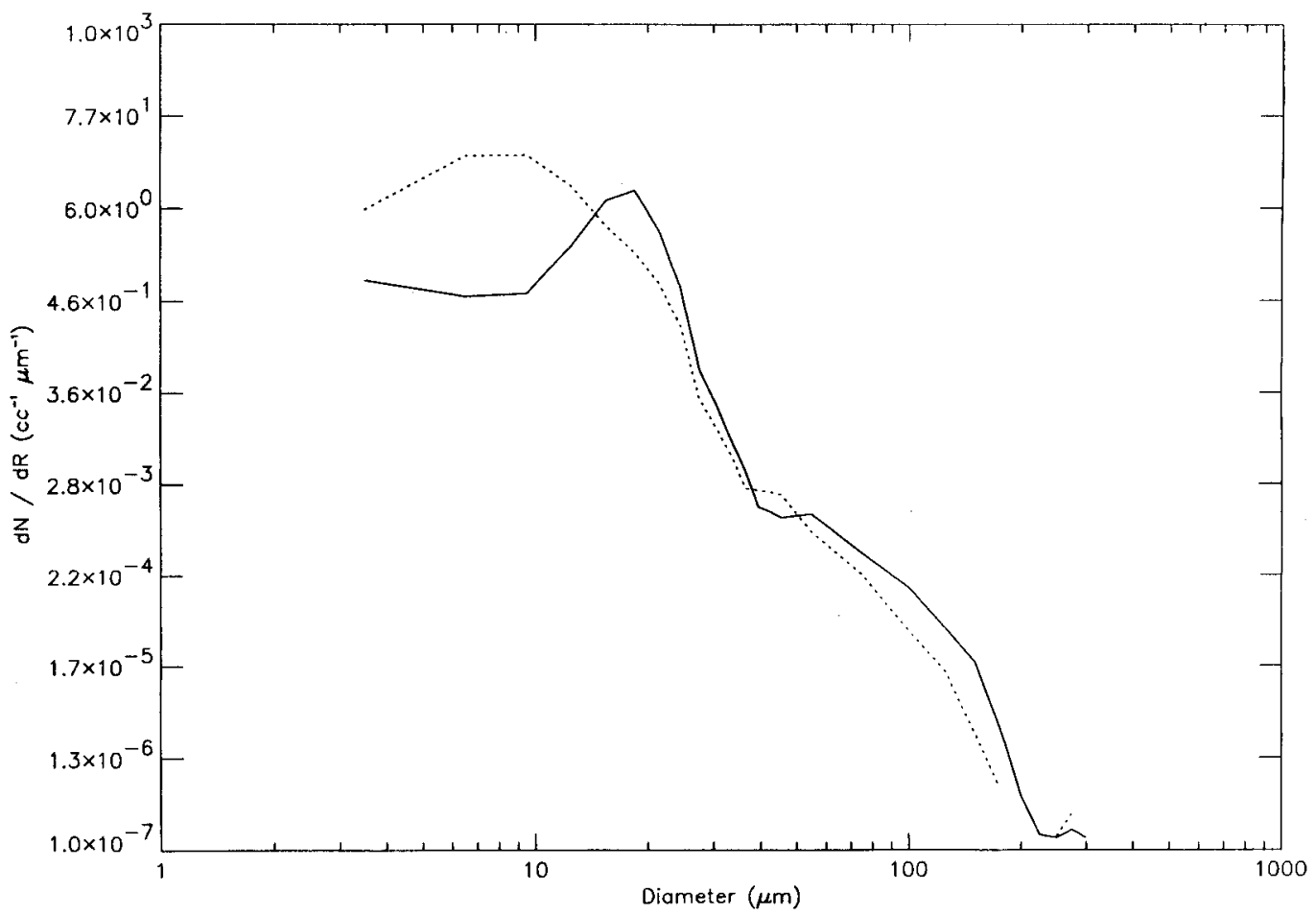

FIG. 5. Cloud and drizzle drop size distributions for ambient cloud (solid lines) and the ship track (dashed lines) measured on 8 Jun 1994 downwind of the Hyundai Duke.

quickly diluted, but even at $40 \mathrm{~km}$ from the ship, peak concentrations were around $450 \mathrm{~cm}^{-3}$ in a $10-\mathrm{km}$-wide plume. The CCN contained in this plume produced significant changes in the cloud microphysics when they entered the base of the stratocumulus layer. The increases in droplet concentrations and decreases in effective radius in the ship track, compared to the ambient cloud, were the second largest observed in MAST. For example, at $60 \mathrm{~km}$ from the ship the droplet concentrations in the ship track were increased by almost an order of magnitude (to $500 \mathrm{~cm}^{-3}$ ) over those in the ambient cloud, and the effective droplet radius was reduced to nearly $4 \mu \mathrm{m}$. The track here was $15 \mathrm{~km}$ in width and was well correlated with the aerosol (from the ship) beneath the cloud. Unfortunately, there was only enough time to carry out five transects of the plume and cloud track as well as one long run away from the ship along the length of the plume under the cloud. In several of the transects of the cloud track perpendicular to the relative wind, a double structure in the cloud microphysical characteristics was observed. This was probably due to the dynamical structure of the boundary layer through which the ship was steaming. Roll patterns were observed in the cloud; the double structure in the cloud track was likely related to these, since the aircraft transected two rolls in which the ship's plume had been released and dispersed.

In this case, as in the majority of the flights carried out during MAST, due to the dynamical structure of the boundary layer and its effect on the cloud, drizzle was a very sporadic or localized phenomenon. Because the background concentration of drizzle-sized drops was so variable, it is difficult to show that the aerosol perturbation from the ships had a statistically significant impact on suppressing drizzle within the ship track. However, as can be seen from Table 2, for the C-130 flights that encountered drizzle in the ambient clouds, the average drizzle rates within the ship tracks (measured in cloud) were always lower than the average in the ambient cloud. As the ship tracks were all relatively narrow, the averages in the background clouds were always carried out over much larger distances than within the track. It should be noted, however, that there were several occasions where localized drizzle rates within the ship track were higher than those measured just outside the track in the ambient cloud.

Figure 5 shows average droplet spectra measured inside and outside the ship track produced by the Hyundai Duke. These spectra were derived using measurements from the FSSP-100 and OAP-2D-C probes, with suitable averaging carried out in the overlapping measurement ranges of the probes. The significant impact of the plume from the ship can be clearly seen in the shape of the spectra for the small droplet sizes. The mode radius of the droplets in the background air is much larger than in the ship track. Within the ship track, the concentration of droplets in the smallest size bins of the FSSP-100 is much greater than in the ambient cloud. However, drop- 

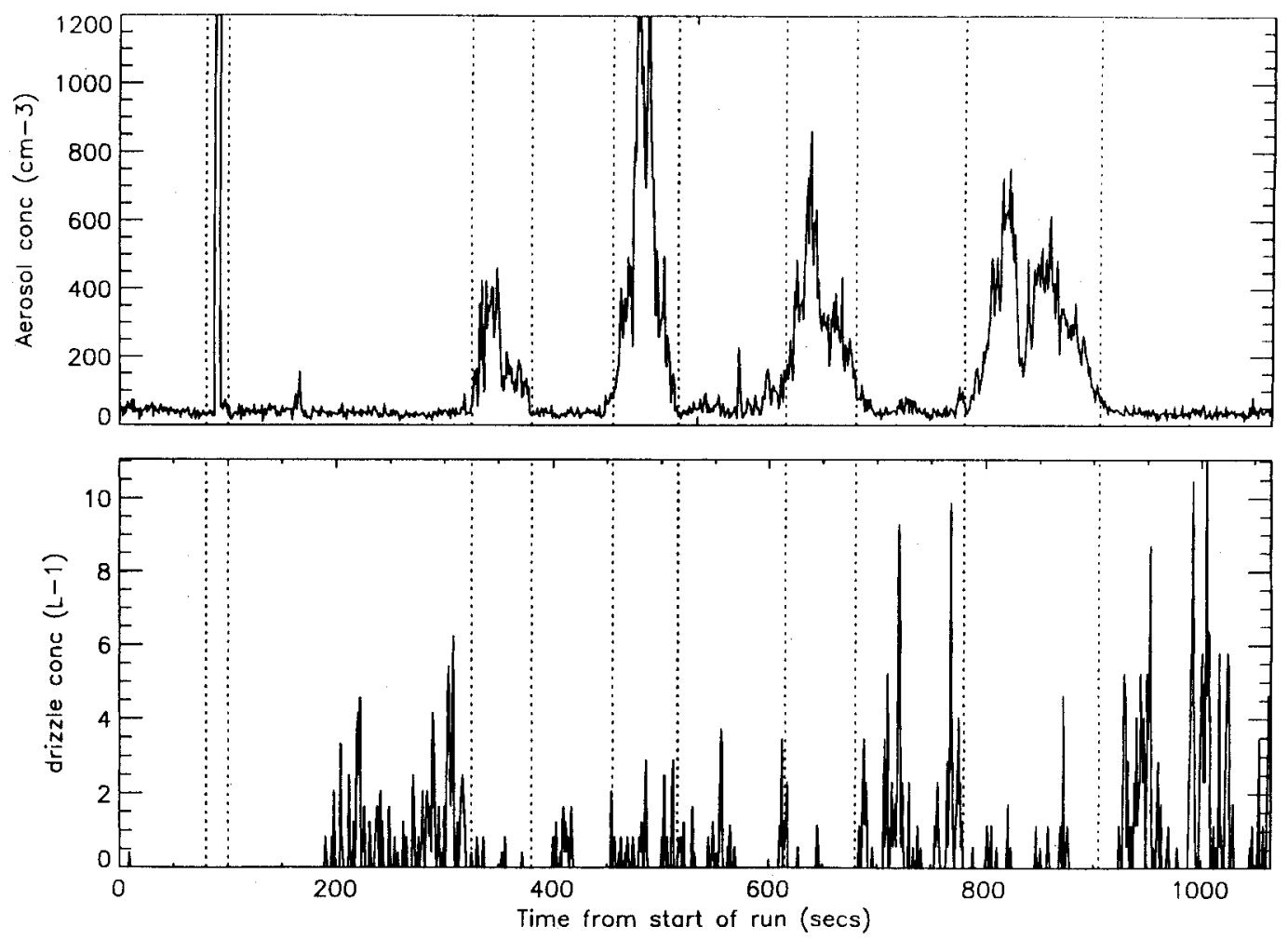

FIG. 6. Time series of concentrations of accumulation-mode aerosol and drizzle drops for five penetrations of the ship track produced by the Hyundai Duke. The edges of ship tracks are denoted by dotted vertical lines.

lets larger than about $60 \mu \mathrm{m}$ in diameter are slightly reduced in number within the ship track, indicating the suppression of drizzle by the aerosol perturbation. Even though there was a large redistribution of the droplet sizes within the spectra, there was no evidence from the measurements that the LWC in the tracks was increased, as would be expected if the LWC flux out of the cloud was decreased by suppression of the larger droplets. If there was any change in LWC, it was masked by the relatively larger ambient variability in LWC. As the drizzle rates measured in the ambient cloud were so light, it is unlikely that any precipitation reached the surface. Therefore, the total LWC in the boundary layer would not be modified by the drizzle, and thus changes in LWC in the cloud would not be expected as long as the height of the cloud base was unaffected and the boundary layer remained well mixed.

During the long run under cloud, and moving away from the ship at an altitude of $500 \mathrm{ft}$, the aircraft made at least five complete transects of the plume. Each time it reentered the plume at a greater distance from the ship. Figure 6 shows time series of the accumulationmode aerosol concentrations, and the number of drizzlesize particles greater than $125-\mu \mathrm{m}$ radius. The first aircraft penetration of the plume was directly overhead of the ship, where the aerosol concentrations farther downwind were high $\left(7000 \mathrm{~cm}^{-3}\right)$ and the plume very narrow. In the subsequent penetrations farther downwind, the aerosol concentrations were lower and the plume progressively wider. In this run the number of drizzle-size droplets encountered was generally small and highly variable, which indicates that drizzle at the surface was highly unlikely. However, there is an indication from these time series that drizzle drop concentrations were lower beneath the ship track, particularly under the older portions of the track.

\section{d. Sanko Peace and Safeguard (13 June 1994)}

On 13 June 1994 the UKMO C-130 investigated the plume from two ships: the USS Safeguard (a U.S. Navy salvage ship), powered by a twin screw diesel engine, and the Sanko Peace, a container vessel with a diesel propulsion unit. A detailed case study (Durkee et al. 2000) reporting on the results of this investigation is included in this issue. The Safeguard was steaming on a preplanned route close to $35.5^{\circ} \mathrm{N}, 122.7^{\circ} \mathrm{W}$, which took it with the wind at $7 \mathrm{~m} \mathrm{~s}^{-1}$ for $3 \frac{1}{2} \mathrm{~h}$, and then on a reciprocal course into wind. The Sanko Peace was encountered at $34.7^{\circ} \mathrm{N}, 122.6^{\circ} \mathrm{W}$ and was heading $280^{\circ}$ at about $8 \mathrm{~m} \mathrm{~s}^{-1}$.

An extensive stratus sheet covered the MAST experimental area and was being advected to the southeast in a moderate to strong northwesterly wind. The air in the boundary layer was extremely clean. The boundary layer was $300 \mathrm{~m}$ deep and capped by a relatively weak 


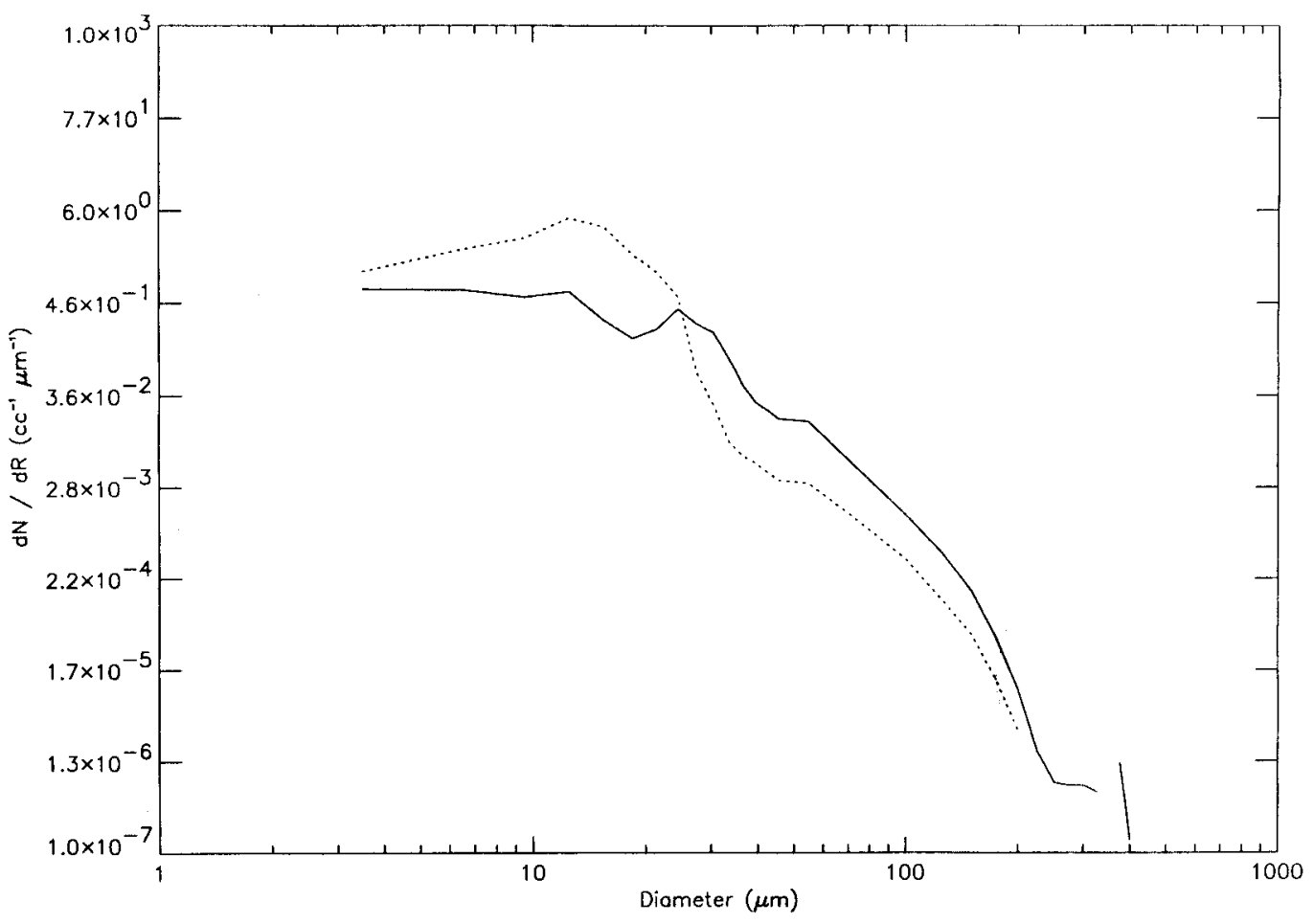

FIG. 7. As for Fig. 5 but for USS Safeguard on 13 Jun 1994.

inversion $(6 \mathrm{~K})$. Cloud base was well below $150 \mathrm{~m}$, which meant that the aircraft was unable to fly underneath it. The only time the aircraft got lower than this was when the cloud broke and the Sanko Peace was visually identified. When this occurred, the aerosol concentrations in the accumulation mode were only 10 $\mathrm{cm}^{-3}$. Maximum LWC was about $0.3 \mathrm{~g} \mathrm{~kg}^{-1}$ and cloud droplet concentrations were very low (between 8 and $20 \mathrm{~cm}^{-3}$ ) with a relatively large effective radius between 12 and $15 \mu \mathrm{m}$. Drizzle-size droplets were measured over large areas. The cloud was observed to have a banded appearance, suggesting the presence of rolls or waves that were aligned approximately parallel with the wind.

Very distinct ship tracks were produced by the Safeguard and the Sanko Peace. In both of these ship tracks, droplet concentrations were increased by an order of magnitude and droplet effective radii decreased to less than $9 \mu \mathrm{m}$. Table 2 shows that this was one of the few cases where drizzle rates were relatively high, at times greater than $2.5 \mathrm{~mm} \mathrm{day}^{-1}$. But there was still a large amount of horizontal variation in the drizzle. On several of the transects through the ship tracks produced by these ships, the average drizzle rate was more than halved. However, there are some instances when drizzle suppression was minimal. Figure 7 shows a combined FSSP and 2D-C droplet spectra comparing the average spectrum in a transect of the ship track produced by the Safeguard with the spectrum in the ambient cloud. Considerable modification of the ambient spectrum was produced by the introduction of aerosol from the ship's plume: droplets larger than about $25 \mu \mathrm{m}$ in diameter were lower, and the concentrations of smaller droplets were higher in the ship track than in the ambient cloud. This is one of the few flights where the measurements indicate that there may have been an increase of LWC within the track due to a reduction of the liquid water flux out of the cloud due to the suppression of drizzle. However, the increases in LWC never amounted to more than $10 \%$, and natural variations in LWC both within the ship track and in the ambient cloud make such changes very difficult to measure.

\section{e. Evergreen Evergenius (28 June 1994)}

On 28 June 1994 the UKMO C-130 investigated the plume and ship track from the Evergreen Evergenius, which was a container ship with a diesel propulsion unit. This was encountered at $1946 \mathrm{UTC}$ at $36.6^{\circ} \mathrm{N}, 125.3^{\circ} \mathrm{W}$ and was heading on a course of $117^{\circ}$ at $8 \mathrm{~m} \mathrm{~s}^{-1}$.

An extensive sheet of stratocumulus cloud covered the ocean off the coast of California. To the south of the area the cloud was quite bright, indicating that there had been some continental influence on the air mass. To the west and north of the area the clouds were darker and had a distinct cellular appearance. The boundary layer was well mixed with a depth of $530 \mathrm{~m}$. Liquid water contents in the cloud peaked at $0.4 \mathrm{~g} \mathrm{~kg}^{-1}$. The aerosol concentrations in the accumulation mode were around $200 \mathrm{~cm}^{-3}$, of which about $100 \mathrm{~cm}^{-3}$ were activated into cloud droplets. Thus, the effective radius of 


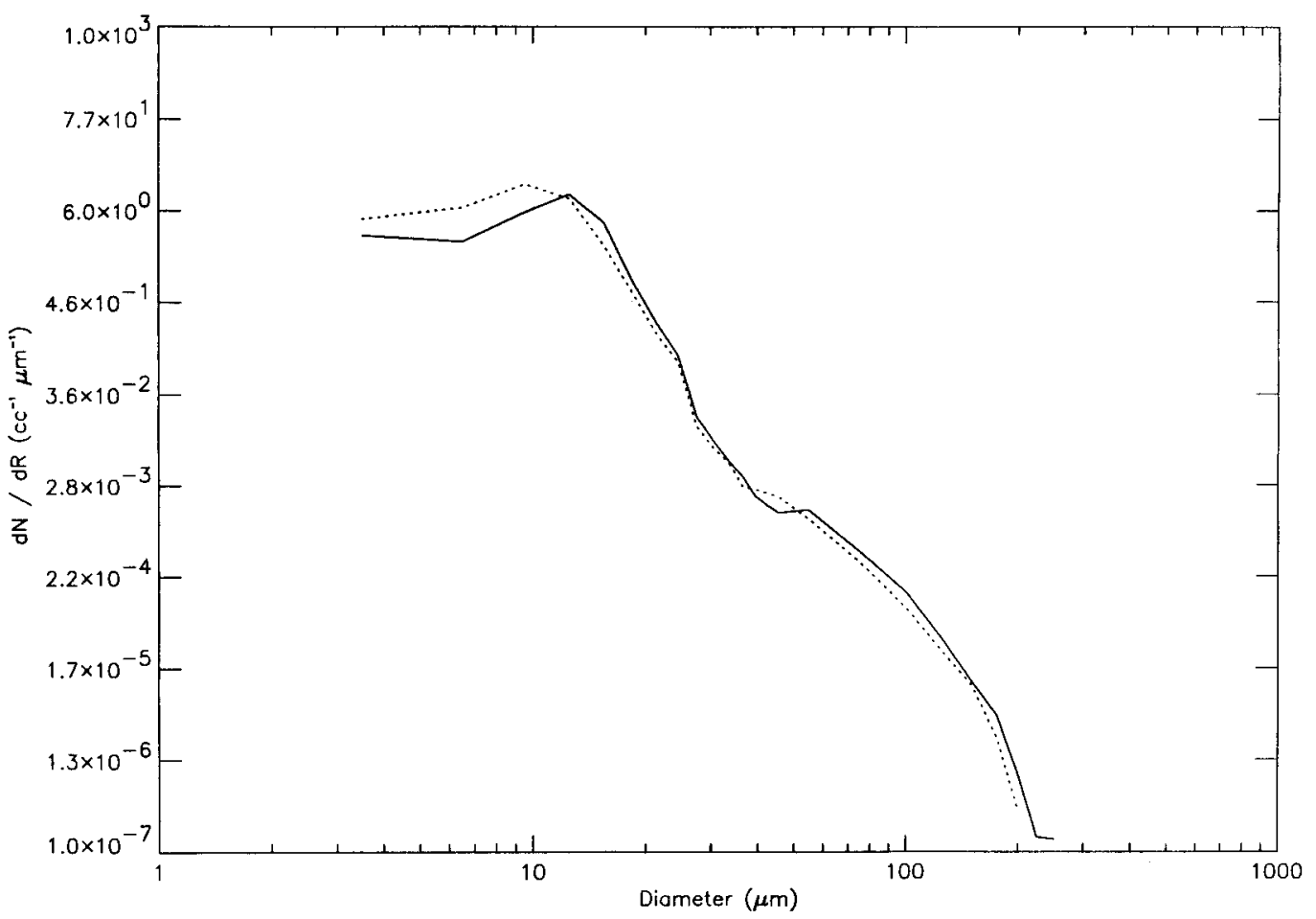

Fig. 8. As for Fig. 5 but for Evergreen Evergenius on 28 Jun 1994 and $70 \mathrm{~km}$ downwind of the ship.

the droplets near cloud top was approximately $9 \mu \mathrm{m}$. Localized patches of drizzle were observed on several occasions in the background boundary layer.

A well-marked plume was observed close to the ship. Aerosol concentrations in the accumulation mode of around $10000 \mathrm{~cm}^{-3}$ were measured when the aircraft penetrated the plume directly over the ship, but this was quickly diluted, and within $10 \mathrm{~km}$ the peak aerosol concentrations had decreased to $1200 \mathrm{~cm}^{-3}$ in a plume that was $3 \mathrm{~km}$ wide. At $70 \mathrm{~km}$ from the ship, the plume had broadened to $12 \mathrm{~km}$ with concentrations of only 450 $\mathrm{cm}^{-3}$. However, at $50 \mathrm{~km}$ from the ship the plume proved difficult to find, even though relatively long flight legs were undertaken. The impact of the plume on the cloud only produced relatively small changes in the microphysics. At most the droplet concentrations increased to $200 \mathrm{~cm}^{-3}$ in the track, and this was fairly consistent along the whole length of the sampled track.

Drizzle rates in the background cloud were quite low. In all of the transects of the cloud track the LWC remained comparable with the ambient cloud values, and there was little indication that drizzle was suppressed in the track. Figure 8 shows an example of the droplet spectra measured in the ship track $70 \mathrm{~km}$ from the ship compared with the spectra measured in the ambient cloud. The concentration of small droplets $(<10 \mu \mathrm{m}$ in diameter) was increased in the ship track, but there is no indication that the variation or size of larger droplets was any different within the ship track than outside of it. In one of the runs beneath cloud, $55 \mathrm{~km}$ from the ship, localized drizzle was encountered almost in the middle of the ship's plume, whereas outside of the track no drizzle was observed. The aerosol concentrations across the plume were very variable and "spiky" in appearance. The run at $25 \mathrm{~km}$ from the ship, shown in Fig. 9, is a very good example of this; it can be seen that at several points in the middle of the plume, aerosol concentrations fell to almost the ambient values before rapidly recovering. This may have been caused by washout of the aerosol by drizzle. The lack of any measurable plume at $55 \mathrm{~km}$ from the ship at a height of $170 \mathrm{~m}$ may be entirely due to washout at an earlier time. If the aerosol perturbations from the ship were not effective at suppressing drizzle, this could have important consequences for the lifetime and dispersion of the plume and therefore the resulting ship track.

\section{f. Hanjin Barcelona (29 June 1994)}

On 29 June 1994 the UKMO C-130 investigated the plume and ship track produced by the Hanjin Barcelona, a container vessel. It was first located at $37.6^{\circ} \mathrm{N}$, $127.5^{\circ} \mathrm{W}$ and was heading toward Long Beach, California, on a course of $118^{\circ}$ at about $11 \mathrm{~m} \mathrm{~s}^{-1}$. This ship produced an extremely long ship track, and the C-130 was able to sample the plume and track at over $150 \mathrm{~km}$ from the ship.

An extensive sheet of stratocumulus cloud covered the ocean off the Californian coast. In the MAST area, the air mass was relatively polluted and the clouds did 


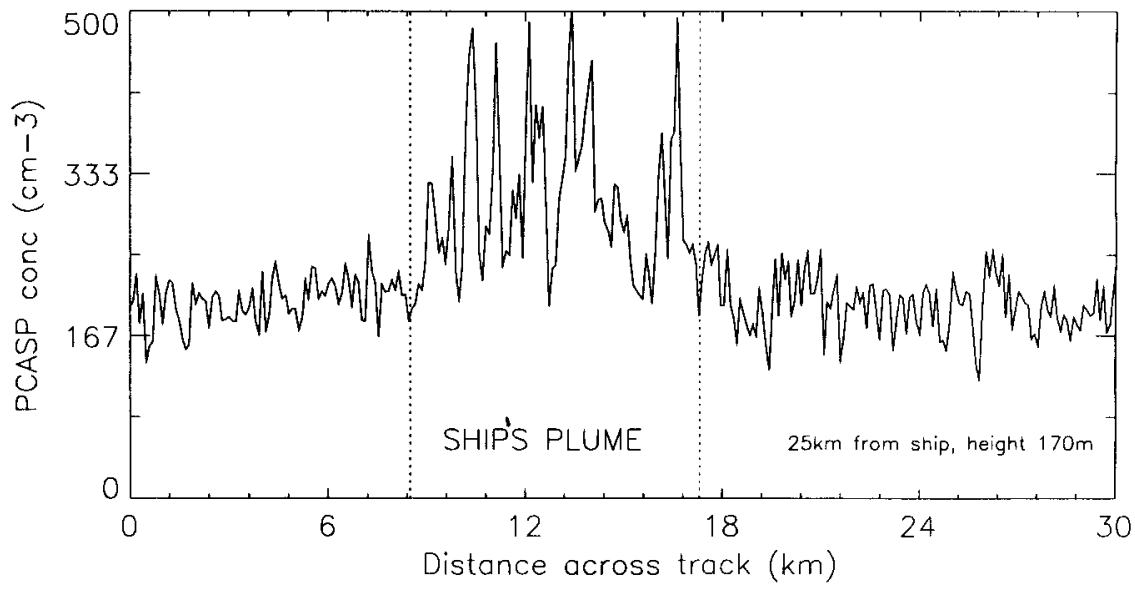

FIG. 9. As for Fig. 6 but for one penetration of the ship track produced by the Evergreen Evergenius on 28 Jun 1994.

not appear to be very susceptible to ship track formation. However, farther to the northwest a maritime air mass was being advected southeastward. The clouds in that region were more broken, and a ship track from the Hanjin Barcelona formed very close to a sharp change in appearance of the cloud sheet, from a continuous unbroken sheet to a very patchy broken layer.

The boundary layer was capped by a sharp temperature inversion at approximately $800 \mathrm{~m}$, and cloud base was close to $500 \mathrm{~m}$. Several profiles through the boundary layer at different times during the flight showed that the cloud layer was weakly decoupled from the surface layer. This was borne out by the observation that some scud and small cumulus clouds were forming at around $300 \mathrm{~m}$.

The cloud microphysical characteristics were typical of a stratocumulus layer in a maritime air mass. The concentrations of accumulation-mode aerosol below cloud base in the ambient air were between 50 and 100 $\mathrm{cm}^{-3}$, although, because of the poor mixing in the boundary layer, there were relatively large variations in the aerosol concentrations with height. The maximum LWC was about $0.7 \mathrm{~g} \mathrm{~kg}^{-1}$ and droplet concentrations were between 30 and $70 \mathrm{~cm}^{-3}$, which resulted in a relatively large peak effective cloud droplet radius (12-13 $\mu \mathrm{m})$.

Even though the boundary layer was decoupled, the plume from the Hanjin Barcelona was detectable at all heights in the boundary layer. Directly over the top of the ship, aerosol concentrations were in excess of 15000 $\mathrm{cm}^{-3}$. Even at distances of $130 \mathrm{~km}$ from the ship, peak values in aerosol concentrations in excess of $300 \mathrm{~cm}^{-3}$ were measured. These aerosols caused relatively large changes in cloud structure when the plume entered the cloud. In general, there was an increase in droplet concentration of between 30 and $40 \mathrm{~cm}^{-3}$, and the effective cloud droplet radius decreased in the ship track to around $7-\mu \mathrm{m}$ radius.

The occurrence of drizzle in the ambient cloud was extremely variable, particularly where the cloud was broken, which was the case during the flight when the aircraft was farthest from the ship. On occasions, drizzle was moderate in intensity but very patchy. This made it very difficult to discern whether the ship track was having a significant impact on suppressing the development of larger drops. From Table 2 it can be seen that, in general, the average drizzle rate in the ship track decreased compared with the average in the ambient cloud, but in one case the drizzle rate in the ship track was more than double that in the ambient cloud. Figure 10 shows a comparison between the cloud particle spectra within the ship track and in the ambient cloud at $100 \mathrm{~km}$ from the ship. The largest differences are again observed in the smallest drops, which are considerably enhanced at drop sizes less than $20-\mu \mathrm{m}$ diameter. There is a small decrease in the larger drops within the track, but it is difficult to separate this from the natural variability present in the ambient cloud.

\section{g. Evidence of drizzle suppression from measurements of liquid water path}

An indication of drizzle suppression would be a change in liquid water path (LWP) between the ambient cloud and a ship track. The UKMO C-130 flew over many ship tracks during MAST, and radiometric measurements were made of the reflectance at visible and near-infrared wavelengths and of the emission at microwave frequencies. Microwave emission was measured using the MARSS, which measures emission at 89 and $157 \mathrm{GHz}$. These measurements can be used to retrieve cloud LWP (English 1995). Unfortunately, several problems were encountered with this instrument that rendered the data unusable for large portions of MAST, and on other occasions, the cloud was too thin for the retrieval to be carried out. The rms accuracy of the retrieval scheme is believed to be around $50 \mathrm{~g} \mathrm{~m}^{-2}$; this is due primarily to uncertainties in the water vapor 


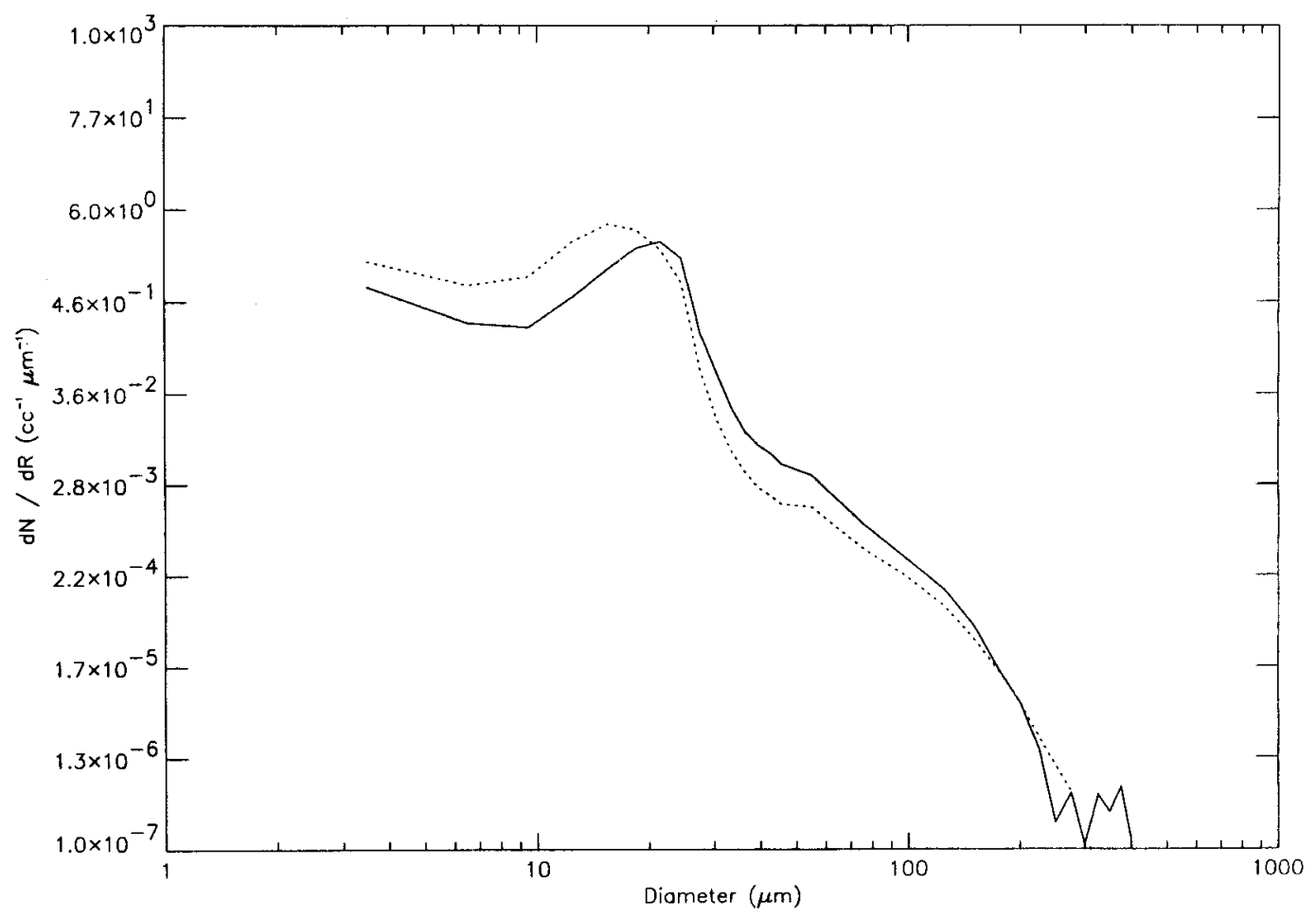

FIG. 10. As for Fig. 5 but for Hanjin Barcelona on 29 Jun 1994.

column and surface emissivity effects. Because the water vapor column and sea surface emissivity are likely to be nearly constant along an aircraft run of about 10 min in length, the sensitivity of the retrieval is high, on the order of 3-16 $\mathrm{g} \mathrm{m}^{-2}$, so the data can be used to identify local changes in LWP.

The LWP can also be derived from reflectance measurements in the visible and near-infrared obtained with the Multi-Channel Radiometer (MCR). Cloud optical depth $(\Delta)$ and cloud droplet effective radius $\left(r_{e}\right)$ can be retrieved using measurements of the reflectance at two wavelengths in the visible or near-infrared. The reflectivity in a spectral region of weak liquid water absorption (e.g., 0.55 or $1.25 \mu \mathrm{m}$ ) is relatively insensitive to changes in $r_{e}$ but monotonically increases with increasing $\Delta$, allowing a retrieval of $\Delta$ by reference to a lookup table of model reflectances for varying clouds. This retrieved delta can then be combined with the reflectance

TABLE 3. Variations of cloud droplet effective radius and liquid water path retrieved from radiometer measurements on the UKMO $\mathrm{C}-130$. The effective radii were retrieved from MCR measurements.

\begin{tabular}{|c|c|c|c|c|c|}
\hline \multirow[b]{2}{*}{ Ship } & \multirow{2}{*}{$\begin{array}{l}\text { Instrument } \\
\text { used } \\
\text { for LWP }\end{array}$} & \multicolumn{2}{|c|}{ Ambient cloud } & \multicolumn{2}{|c|}{ Ship track } \\
\hline & & $\begin{array}{c}r_{e} \\
(\mu \mathrm{m})\end{array}$ & $\begin{array}{c}\text { LWP } \\
\left(\mathrm{g} \mathrm{m}^{-2}\right)\end{array}$ & $\begin{array}{c}r_{e} \\
(\mu \mathrm{m})\end{array}$ & $\begin{array}{c}\text { LWP } \\
\left(\mathrm{g} \mathrm{m}^{-2}\right)\end{array}$ \\
\hline Sanko Peace & MCR & 19.4 & 71.2 & 9.2 & 100.7 \\
\hline COSCO Tai He & MCR & 8.3 & 45.5 & 7.3 & 45.5 \\
\hline Hanjin Barcelona & MARSS & 13.8 & 124.7 & 6.9 & 188.8 \\
\hline Hanjin Barcelona & MARSS & 15.1 & 161.2 & 9.5 & 226.8 \\
\hline
\end{tabular}

at a wavelength of strong liquid water absorption (e.g., 2.01 or $2.26 \mu \mathrm{m}$ ) to retrieve $r_{e}$. A thorough description of the scheme is given by Rawlins and Foot (1990), and an improvement to the scheme is given by Taylor (1992). An estimate of the LWP can then be made using the relation

$$
\text { LWP }=2 r_{e} \Delta / 3 .
$$

The retrieval of cloud microphysical properties using the MCR fails for optically thin clouds and cannot be interpreted if there is an upper layer of cloud (such as cirrus) that modifies the downwelling radiance.

During the MAST experiment the background LWP was found to vary greatly, sometimes in excess of 80 $\mathrm{g} \mathrm{m}^{-2}$ along a $10-\min (60 \mathrm{~km})$ run. Due to the limitations of the techniques described above, only four cases from three different ships were identified in which the ship track was clearly distinguishable from the ambient cloud. Results for these four cases are given in Table 3.

For three of the cases listed in Table 3 there were significant increases in the LWP in the ship track compared to that in the ambient cloud. In the Sanko Peace case this was due in part to the ship track being elevated by approximately $100 \mathrm{~m}$ above the ambient cloud. Modification of the LWP occurred only in clouds that had relatively large cloud droplet effective radii in the ambient cloud. Han et al. (1995) used ground-based microwave radiometer and ceilometer data to determine the presence of drizzle over San Nicolas Island, California. They then compared the occurrence of drizzle 


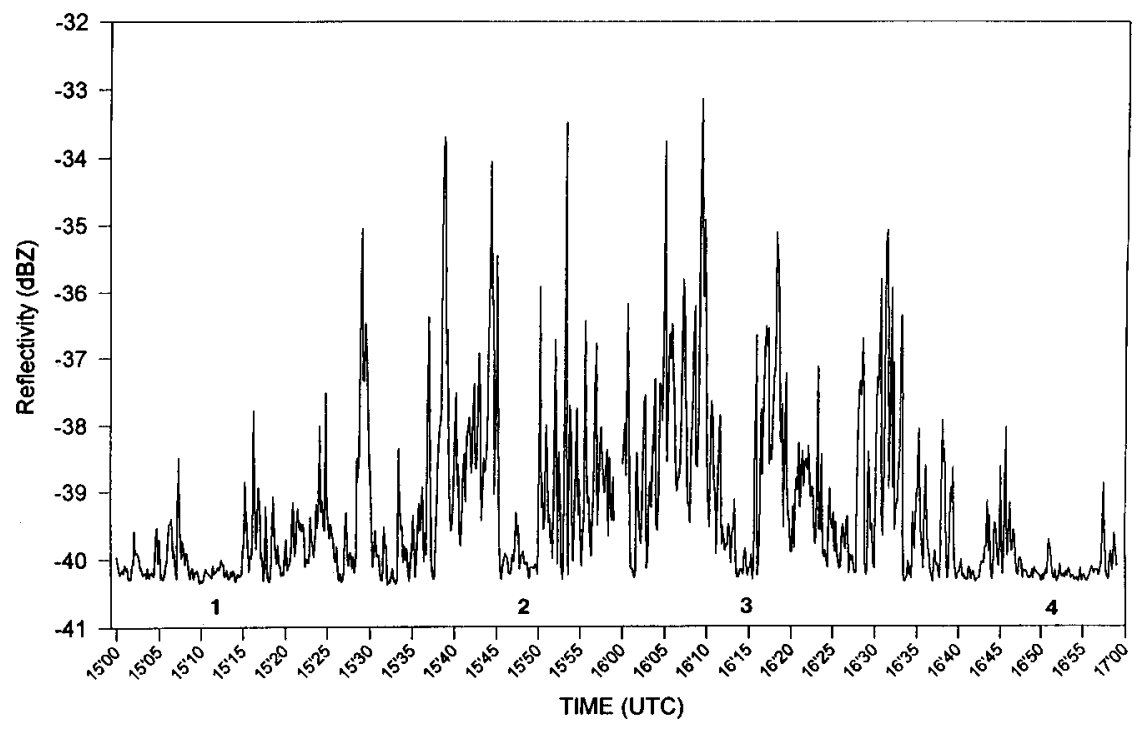

FIG. 11. Radar reflectivity at $300 \mathrm{~m}$ from the Pennsylvania State University 94-GHz radar operating from the R/V Glorita. Four ship track crossings are indicated by the brackets at the bottom of the graph. Crossings 1 and 3 were accompanied by increases in CCN concentrations at ship level.

episodes with effective radii retrieved from the International Satellite Cloud Climatology Project (ISCCP) satellite data. Han et al. suggested that clouds with effective cloud droplet radii $>15 \mu \mathrm{m}$ at cloud top appeared to be associated with drizzle episodes, whereas those with effective radii $<10 \mu \mathrm{m}$ were not. These results are consistent with measurements by Gerber (1996), and the retrievals presented here, where changes in LWP, assumed to be associated with drizzle suppression, are observed only in the cases where $r_{e}>10$ $\mu \mathrm{m}$. However, more data in clouds with both low and high $r_{e}$ values at cloud top are required to verify these results. Despite the limitations in the measurements presented here, they indicate that increases in cloud droplet concentrations in ship tracks, which lower droplet sizes, can alter the LWP.

\section{h. Evidence for drizzle drop modification from measurements aboard the $R / V$ Glorita}

Observations from the $94-\mathrm{GHz}$ radar on the $\mathrm{R} / \mathrm{V}$ Glorita during MAST provided further support for the suppression of drizzle in ship tracks. From 1500 to 1700 UTC on 28 May 1994, remote sensing and in situ measurements were made from the R/V Glorita while it was operating 10-30 km downwind from the USS Mount Vernon, a U.S. Navy landing ship propelled by a steam turbine engine and fueled by navy distillate fuel (Hobbs et al. 2000). As the Mt. Vernon moved northwest at $\sim 10$ $\mathrm{m} \mathrm{s}^{-1}$, the R/V Glorita sailed a pattern downwind that resulted in four crossings, separated by 20-30 $\mathrm{min}$, beneath clouds affected by the plume from the Mt. Vernon. A detailed description of the instrumentation on the R/V Glorita and of the cloud and boundary layer structure observed during this observing period is given by Demme (1996).

A solid stratocumulus cloud deck was present over the area during the observing period. A laser ceilometer indicated a cloud-base height of about $300 \mathrm{~m}$, and soundings taken from the R/V Glorita indicate a wellmixed boundary layer with an inversion at about 550 $\mathrm{m}$. The LWP derived from a microwave radiometer (Han and Thomson 1994) was about $300 \mu \mathrm{m}$. Aircraft observations made with the C-131A aircraft upstream from the area of ship operations indicated cloud droplet concentrations of $200 \mathrm{~cm}^{-3}$ with effective radius between 4 and $8 \mu \mathrm{m}$.

The Pennsylvania State University $94-\mathrm{GHz}$ radar (Clothiaux et al. 1995) was operated aboard the R/V Glorita during this time period in an upward-looking mode that gave a vertical resolution of $75 \mathrm{~m}$ and a temporal sampling of approximately $10 \mathrm{~s}$. Although no ship track was detected from satellite observations, the radar reflectivity from heights of 75-450 $\mathrm{m}$ was reduced by 2-3 dB as the R/V Glorita passed under clouds that were modified by the plume from the USS Mt. Vernon. The reflectivity from the radar at a height of $300 \mathrm{~m}$ for a 2-h observing period is shown in Fig. 11. Although there is considerable variability in the reflectivity due to natural variations in cloud and drizzle structure, the signatures at the crossing points beneath the ship track are fairly well defined, particularly at 1545-1550 and 1610-1615 UTC. Furthermore, within the reduced-reflectivity regions there is a substantial decrease in the temporal variability of the reflectivity. This is illustrated in Fig. 12 by the deviations of the reflectivity from the hourly means. Outside of the ship track there is considerable small-scale variability in the reflectivity structure. Al- 


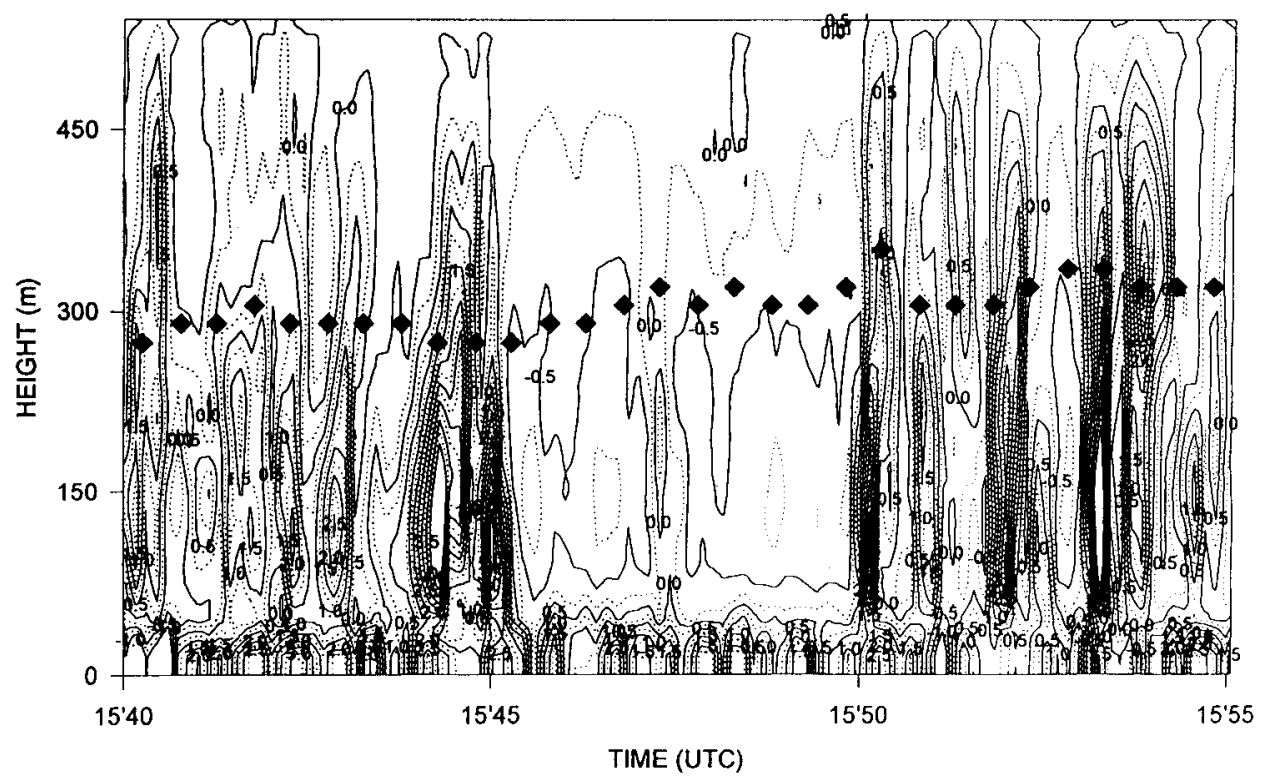

FIG. 12. Perturbation in radar reflectivity at $0.5-\mathrm{dB}$ intervals for a crossing of the ship track labeled 2 in Fig. 1. The perturbations represent deviations from the reflectivity averaged from 1500 to 1600 UTC at each range gate. Solid symbols indicate cloud-base height from the laser ceilometer.

though these clouds had effective droplet radii somewhat smaller than the drizzle threshold, since the structures extended well below the cloud base indicated by the ceilometer, they can be interpreted as reflectivity variations due to large drops falling out of the stratus deck. These structures also show good vertical coherence, extending well into the cloud layer, and display temporal variability on scales of 1-2 min. Since the wind speeds in the boundary layer were about $10 \mathrm{~m} \mathrm{~s}^{-1}$, the temporal fluctuations observed from the ship correspond to spatial variations of $\sim 600-1200 \mathrm{~m}$. This spatial scale corresponds to large eddy updraft and downdraft circulations that are observed in marine stratocumulus (Penc and Albrecht 1987). What is striking is that the 1-2-min fluctuations in the radar reflectivity are almost completely suppressed in the re-

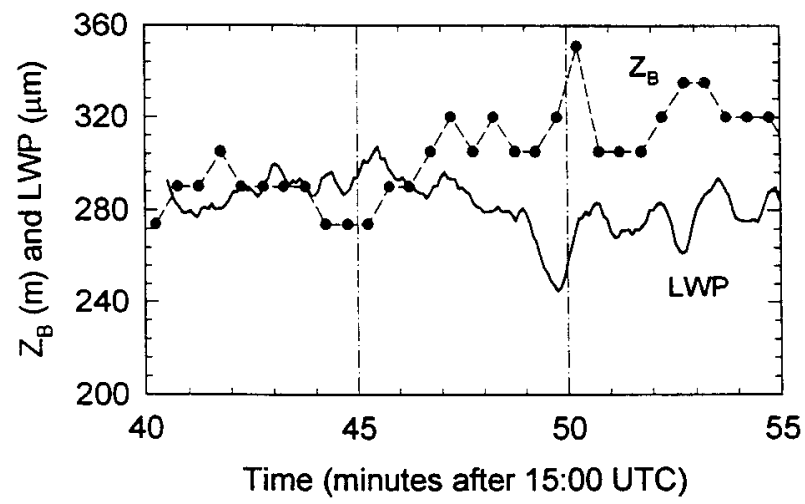

FIG. 13. Cloud base height $\left(Z_{b}\right)$ from a laser ceilometer and integrated LWP from a microwave radiometer on the R/V Glorita. Dashed vertical lines indicate the boundaries of the ship track indicated by radar reflectivity measurements. gion of the track. Observations from the UW C-131A in the ambient cloud on this day indicate a cloud LWC of about $0.3 \mathrm{~g} \mathrm{~m}^{-3}$, with approximately 30 droplets per liter with radii greater than $25 \mu \mathrm{m}$.

The reduced radar reflectivity in the ship track compared with the ambient cloud could be explained by a reduction in the concentration of larger droplets, a reduction in the size of the droplets, or a combination of these two effects. For a monodispersed population of $30-\mu \mathrm{m}$ droplets and a concentration of 30 per liter, the radar reflectivity would be $-28 \mathrm{dBZ}$. A 3-dBZ decrease in reflectivity could be explained by either a $50 \%$ decrease in the concentration of these large droplets or a decrease of $3 \mu \mathrm{m}$ in the mean droplet radius. Unfortunately, the Doppler processor was not operating on the radar during this time period, so we are unable to infer droplet sizes from their fall speeds.

The LWP and the cloud base varied across the ship track (Fig. 13). Although the cloud-base height increases and the LWC decreases across the track, it is not clear that these changes are related to the ship track, since there is considerable natural variability in the ambient cloud. There is also not a clear signal in the LWP in the other three crossings of the ship track, even though they were all associated with a well-defined decrease in the variability of the radar reflectivity. Thus, for this cloud, which apparently had relatively little drizzle, there is no evidence of an increase in LWC in the ship track, despite a clear reduction in large droplets in the track.

\section{Modeling results}

Two modeling approaches were used to explore the relationships between drizzle and cloud water in ship 
tracks. First is a 1D turbulence closure model that treats in considerable detail the interactions between aerosol and cloud microphysics, radiative transfer, and turbulent mixing in the marine boundary layer (Ackerman et al. 1995a). Second is a 3D large eddy simulation (LES) model that treats the same interactions but includes a more detailed description of air motions (Kogan et al. 1995).

\section{a. Model simulations of drizzle suppression in ship tracks with a $1 D$ cloud model}

Albrecht (1989) suggested that smaller average droplet sizes resulting from increased cloud droplet concentrations in ship tracks should result in less drizzle because droplet collisions should be reduced. As a result of the reduction in the removal of cloud water by drizzle, the LWC in ship tracks should be higher than in the ambient cloud. Ackerman et al. (1995b) and Durkee et al. (2000) used detailed numerical models to investigate the effects of CCN injections into marine stratiform clouds. In support of Albrecht's hypothesis, they found that increased droplet concentrations resulted in increased maximum values of cloud water. However, the LWC was enhanced only in the upper reaches of their simulated cloud layers. In the lower regions, the increased droplet concentrations resulted in decreased cloud water. Here we briefly describe their modeling approach and results.

The 1D numerical model of Ackerman et al. (1995a) consists of three modules: a microphysics module that explicitly resolves the size distributions of aerosols and cloud droplets and treats the warm-cloud microphysical processes that affect them; a sophisticated radiative transfer module that calculates cloud optical properties and heating rates; and a turbulence kinetic energy closure model that computes eddy diffusion mixing coefficients. Ackerman et al. (1995a) showed that results of simulations with this model compare favorably with detailed observations on marine stratiform clouds (Nicholls 1984), and the responses of the model to changes in boundary conditions are also consistent with observations (Nicholls and Leighton 1986). The shortcoming of 1D models is that by averaging over updrafts and downdrafts, the expected peak supersaturations in updrafts near cloud base are not represented, and the lower half of the simulated cloud layer is slightly subsaturated. Also, 1D models treat drizzle as a horizontally homogeneous process, whereas in the atmosphere it tends to be patchy. This simplification may result in an exaggerated sensitivity of cloud water to changes in drizzle fluxes.

Here we summarize the results from two sets of simulations (one initialized at local midnight, the other at local noon) using the Ackerman et al. (1995a) model: the ship track produced by the Sanko Peace during MAST, as reported by Durkee et al. (2000); and the ship track intersected during the First ISCCP Regional Experiment experiment off the coast of southern California, as reported by Radke et al. (1989) and King et al. (1993).
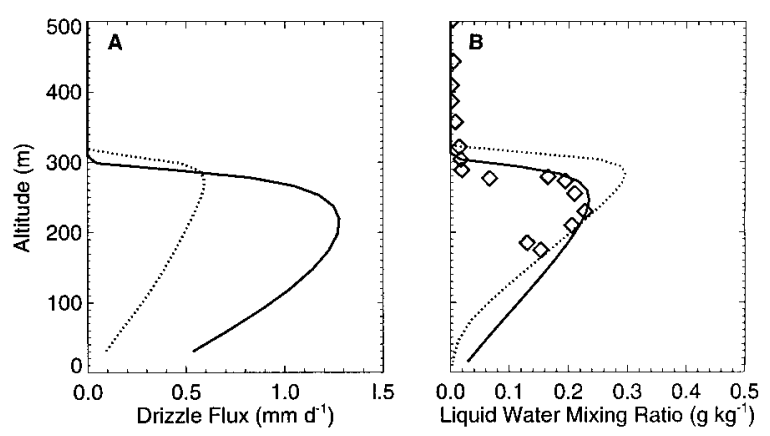

FIG. 14. Modeled profiles of (a) drizzle flux and (b) liquid water mixing ratio $1 \mathrm{~h}$ after a $\mathrm{CCN}$ injection at noon. The solid lines are for the control run (ambient cloud) and the dotted lines are for the ship track simulation. In (a) the profile of liquid water measured from the $\mathrm{C}-130$ in the ambient cloud is overlaid with diamonds.

Details of the model simulations are given by Durkee et al. (2000) and by Ackerman et al. (1995b), respectively.

Starting at local midnight (noon), ambient conditions were simulated for 12 (24) h, using observed, fixed boundary conditions (the values in parentheses are for the second set of simulations). Then at noon (midnight), each simulation was split into two: in the control run the simulation was allowed to continue unperturbed, while in the ship track run a $\mathrm{CCN}$ injection (representing the ship exhaust) was instantaneously released at $100-\mathrm{m}$ altitude, and this simulation was allowed to evolve independently. Because a 1D model cannot represent horizontal dispersion, it is assumed that the CCN injection is immediately spread over the width of a representative plume.

In the model simulation of the ship track produced by the Sanko Peace, the CCN mix upward into the cloud layer where the droplet concentrations rapidly increase from 15 to $\sim 90 \mathrm{~cm}^{-3}$ (recorded in the first model output, $1 / 2 \mathrm{~h}$ after the CCN injection). This increase in droplet concentrations produces a decrease of the droplet effective radius ( $1 \mathrm{~h}$ after the $\mathrm{CCN}$ injection) from $\sim 20$ to $11 \mu \mathrm{m}$, which is in agreement with the measurements. The smaller droplets are less effective at producing precipitation (because their fall speeds and collection efficiencies are smaller), and the drizzle flux decreases, as seen in Fig. 14a (in these calculations the drizzle flux is summed over all droplet sizes). The maximum (surface) drizzle flux decreases from $1.3(0.5) \mathrm{mm} \mathrm{day}^{-1}$ in the ambient cloud to $0.6(0.1) \mathrm{mm} \mathrm{day}^{-1}$ in the ship track. The reduced drizzle allows the LWC to increase in the upper part of the ship track (shown in Fig. 14b): the maximum liquid water increases from $0.22 \mathrm{~g} \mathrm{~kg}^{-1}$ in the ambient cloud to $0.3 \mathrm{~g} \mathrm{~kg}^{-1}$ in the ship track. [The boundary layer also deepens in the ship track simulation due to a feedback between turbulent mixing and cloud optical depth at such low ambient droplet concentrations, as discussed by Ackerman et al. (1993, 1995b).] Surprisingly, below an altitude of $210 \mathrm{~m}$ (in a boundary layer that is only $\sim 300 \mathrm{~m}$ deep) cloud water is reduced in the ship track. The cloud water is greater in the ambient cloud due to the increased drizzle flux 

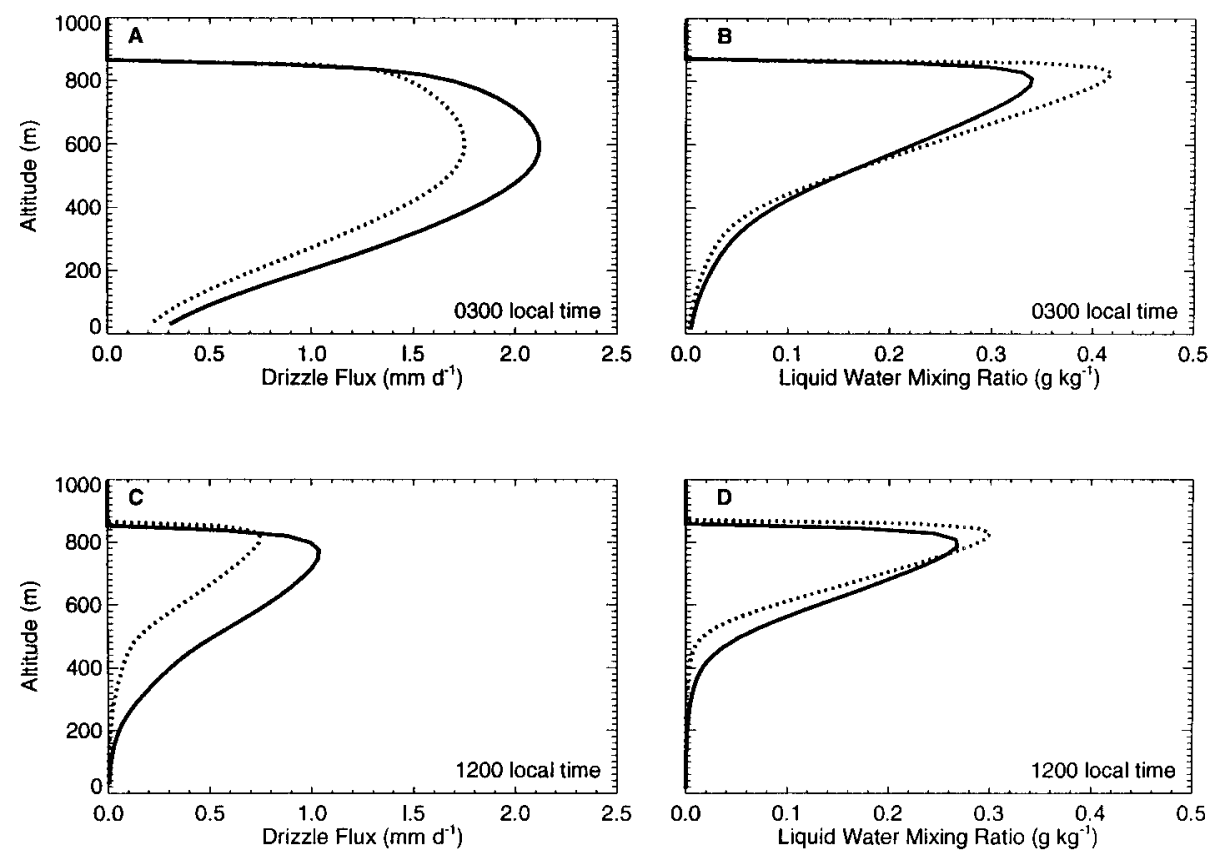

FIG. 15. Modeled profiles of (a), (c) drizzle flux and (b), (d) liquid water mixing ratio. (a) and (b) are $3 \mathrm{~h}$ after an injection of CCN at midnight; (c) and (d) are taken $12 \mathrm{~h}$ after the $\mathrm{CCN}$ injection. The solid lines are for the control run (ambient cloud) and the dotted lines are for the ship track simulation.

from the upper part of the cloud layer, which is physically plausible. Additionally, the smaller droplets in the ship track evaporate more rapidly in the subsaturated lower region of the cloud layer, which is more of an artifact of the $1 \mathrm{D}$ model.

In Ackerman et al.'s (1995b) simulation of the ship track reported by Radke et al. (1989), within $3 \mathrm{~h}$ after an injection of $\mathrm{CCN}$ at midnight, the droplet concentrations increased from 40 to $100 \mathrm{~cm}^{-3}$ in the 850 -m-deep boundary layer. This represents a smaller relative increase, and a slower response, than in the preceding simulation (in which a shallower boundary layer was simulated). The cloud droplet effective radius decreased from 17 to $13 \mu \mathrm{m}$, which produced a decrease in drizzle flux in the ship track, as shown in Fig. 15a. The maximum drizzle flux decreased from $2.4 \mathrm{~mm} \mathrm{day}^{-1}$ in the ambient cloud to $2 \mathrm{~mm} \mathrm{day}{ }^{-1}$ in the ship track. This moderate decrease resulted in an increase of maximum LWC from 0.34 to $0.42 \mathrm{~g} \mathrm{~kg}^{-1}$. As in the preceding simulation, the region of cloud water enhancement was limited to the upper region of the ship track; below $500 \mathrm{~m}$ the liquid water in the ambient cloud slightly exceeded that in the ship track. After the sun rises, mixing in the simulated boundary layers decreased because solar absorption offset the cloud-top longwave cooling that was driving the boundary layer mixing, and both simulated cloud layers thinned. This resulted in a decrease in drizzle and cloud water in both simulated boundary layers (Figs. 15c, d). By noon, the region of enhanced cloud water in the ship track was limited to the upper $100 \mathrm{~m}$ of the cloud layer (Fig. 15d), and the increase in maximum cloud water was modest at that time, from $0.27 \mathrm{~g} \mathrm{~kg}^{-1}$ in the ambient cloud to $0.3 \mathrm{~g} \mathrm{~kg}^{-1}$ in the ship track.

Comparing the two model simulations, it is evident that the dependence of cloud LWC on cloud droplet concentration weakens as the ambient droplet concentrations increase. Additionally, the simulations show that when solar absorption significantly reduces boundary layer mixing (which occurs only in the simulation with greater droplet concentrations), the region of enhanced cloud LWC is restricted to a small fraction of the cloud layer near cloud top.

\section{b. Simulations of drizzle suppression using an LES model}

In addition to the ambient $\mathrm{CCN}$ concentration, the heat and moisture fluxes, which depend strongly on the boundary layer structure, can also significantly affect the process of drizzle formation and evolution. These effects are illustrated here using the Cooperative Institute for Mesoscale Meteorological Studies LES model that combines 3D dynamics with an explicit formulation of the liquid phase microphysical processes (Kogan et al. 1995). The dynamical framework is based on a finitedifference discretization using the staggered Arakawa $\mathrm{C}$ grid. The advective transport of momentum is computed using a flux-conserving advection scheme analogous to that described by Tremback et al. (1987), with an option to select the order of spatial accuracy from the second to the fifth. The time integration is performed using the third-order Adams-Bashforth scheme. The nu- 


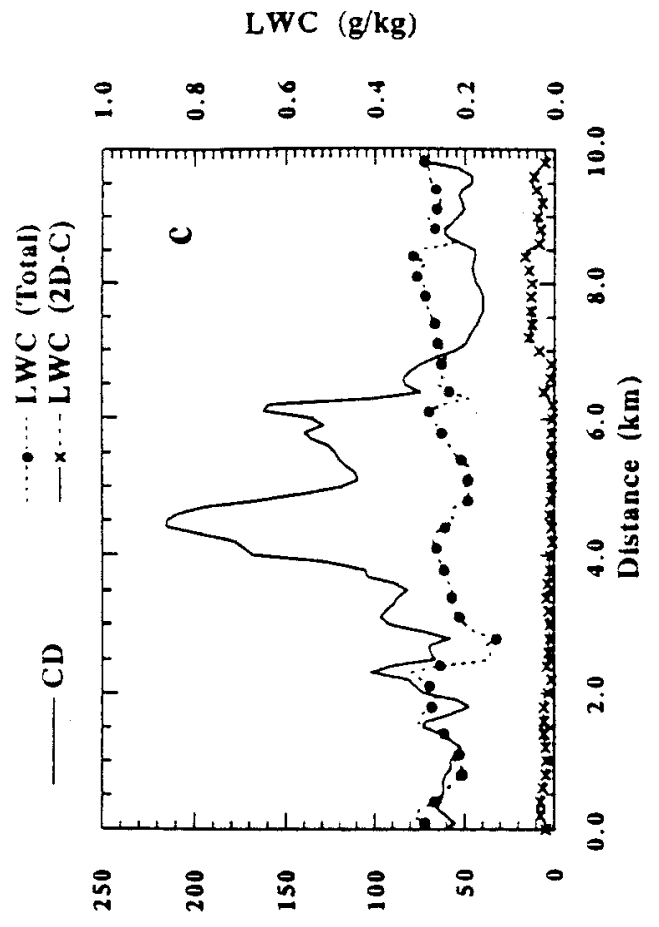

(e.uo) nolnesuajuoj dosa pnols

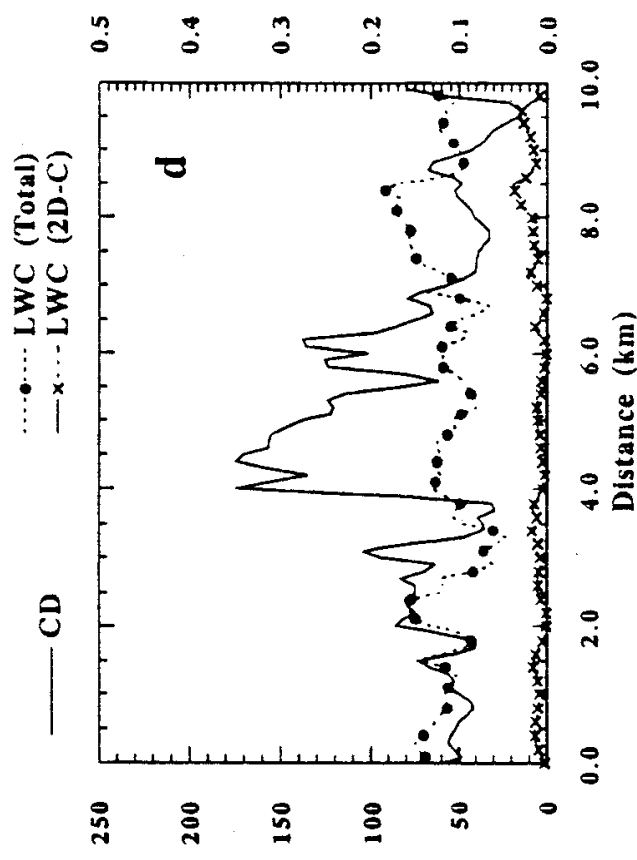

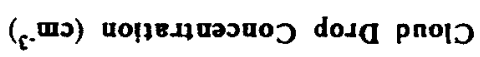

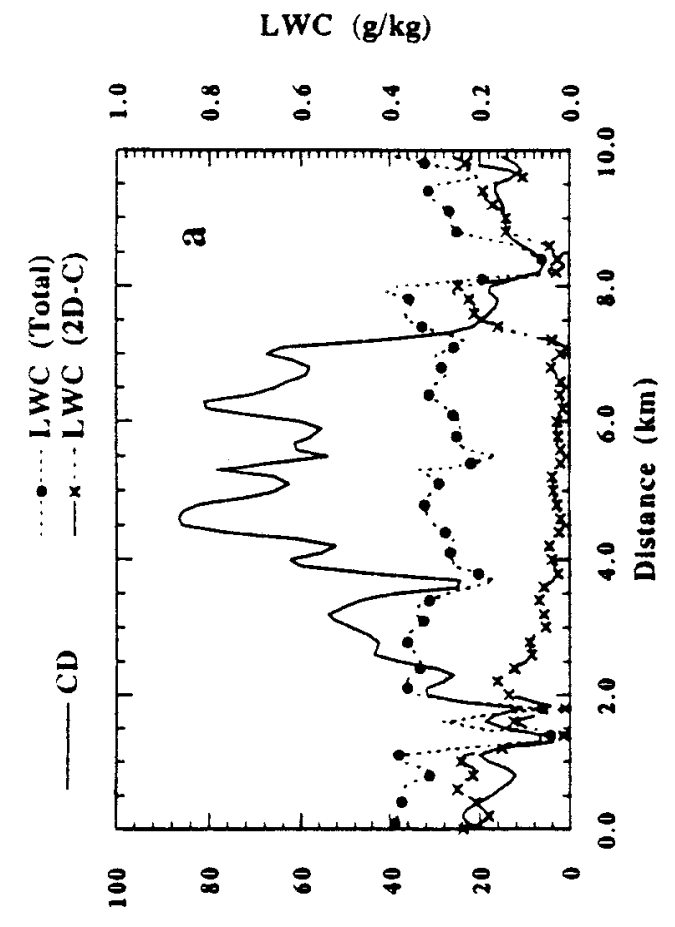

(c. «o) do!leduarsuoj dosa pnolo

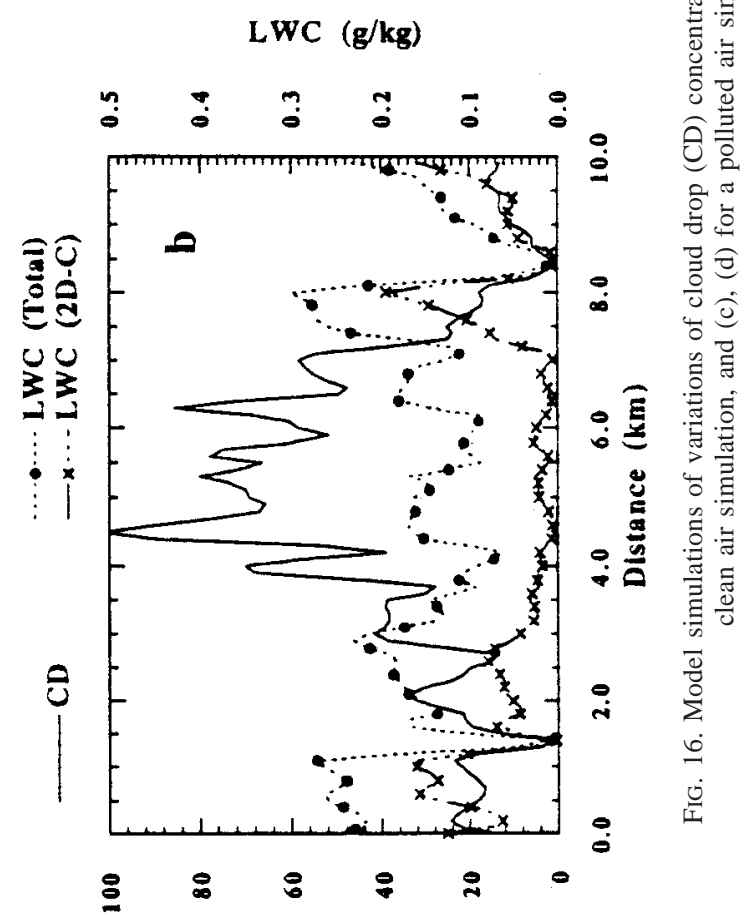

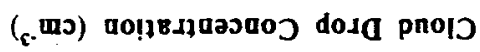




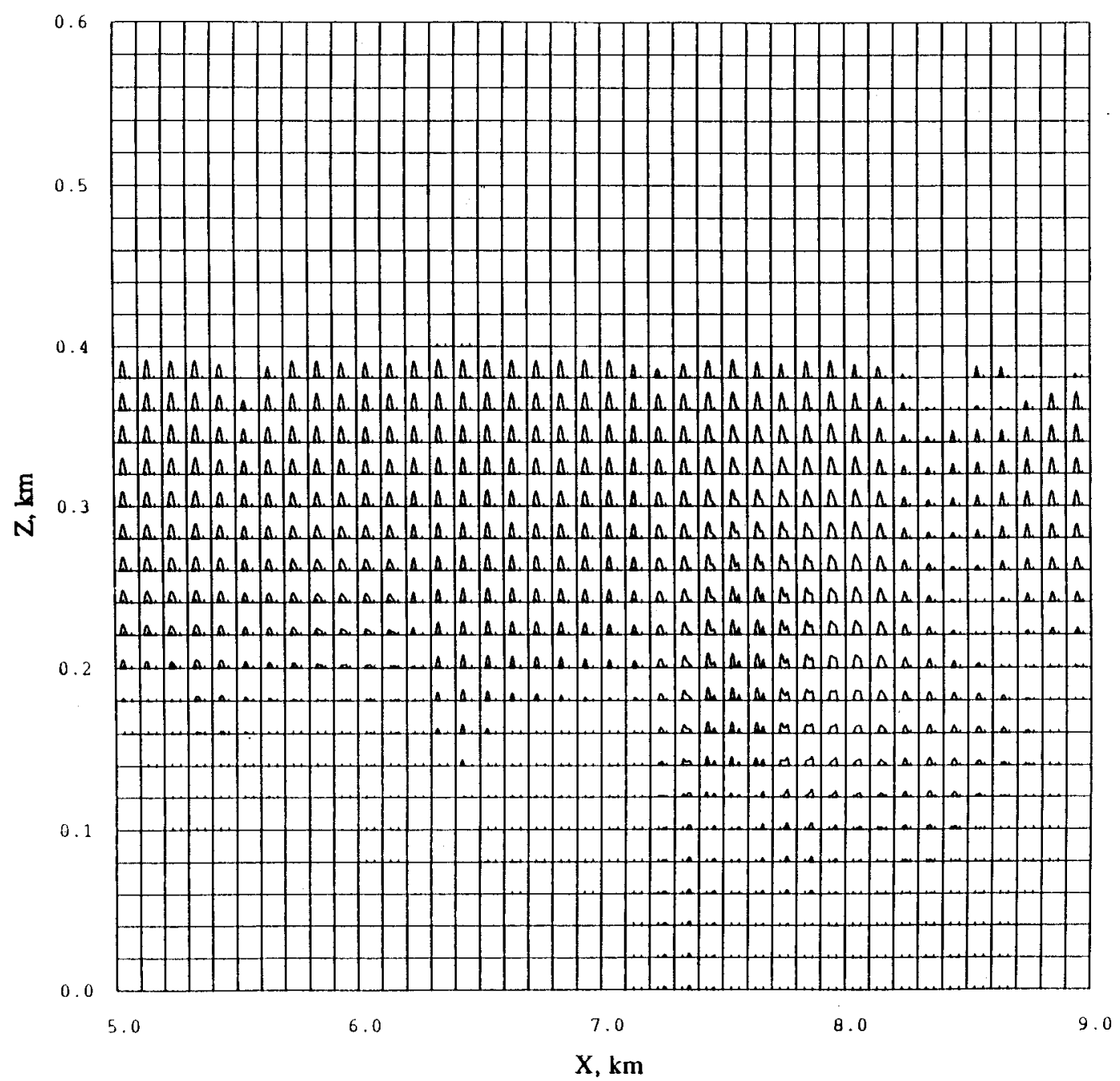

FIG. 17. Cloud drop spectra at various points in the vertical cross section for the clean air simulation. Each box shows the mass distribution function vs $\log r$. The two tick marks in the empty boxes in the lower left corner of the plot correspond to a drop radius of 10 and $100 \mu \mathrm{m}$, respectively.

merical scheme is described in detail by Khairoutdinov and Kogan (1999). Cloud physical processes are treated explicitly based on the prediction equations for $\mathrm{CCN}$ (19 categories) and cloud drop spectra (25 categories) (Kogan 1991; Kogan et al. 1995). To calculate broadband solar heating and longwave cooling rates at each grid point and at each time step, the model uses the computationally efficient broadband radiation package described by Wyant et al. (1997). The more detailed description of the model and initialization procedure is provided in the paper by Liu et al. (2000).

We first show results from two simulations of ship tracks produced in clean air and in a more polluted air. The thermodynamical structure of the boundary layer was identical in both simulations and initialized to match the measurements of the UKMO C-130 flight on 8 June 1994 at the time the Hyundai Duke ship track was observed. The simulations differed in the ambient
$\mathrm{CCN}$ concentration. The latter was specified such that the resulting drop concentration in the ambient cloud was about $25 \mathrm{~cm}^{-3}$ in the first simulation and about 80 $\mathrm{cm}^{-3}$ in the second simulation.

The curves in Fig. 16 show variations across the ship track of the drop concentration, the total LWC, and the drizzle LWC in simulations of clean (Figs. 16a,b) and a more polluted air (Figs. 16c,d). Figures 16a,c and $16 \mathrm{~b}, \mathrm{~d}$ represent the cloud-top and cloud-base levels, respectively. The ship track is evident by an increase in the drop concentration in the region from about 4 to 7 $\mathrm{km}$. Significant reduction of the drizzle LWC is evident in the simulation of the clean case, both at cloud top (Fig. 16a) and at cloud base (Fig. 16b). In the polluted case (Figs. 16c,d), however, the drizzle liquid water is much smaller in the ambient cloud outside the ship track. Therefore, the reduction of drizzle, although noticeable, is not statistically significant. 

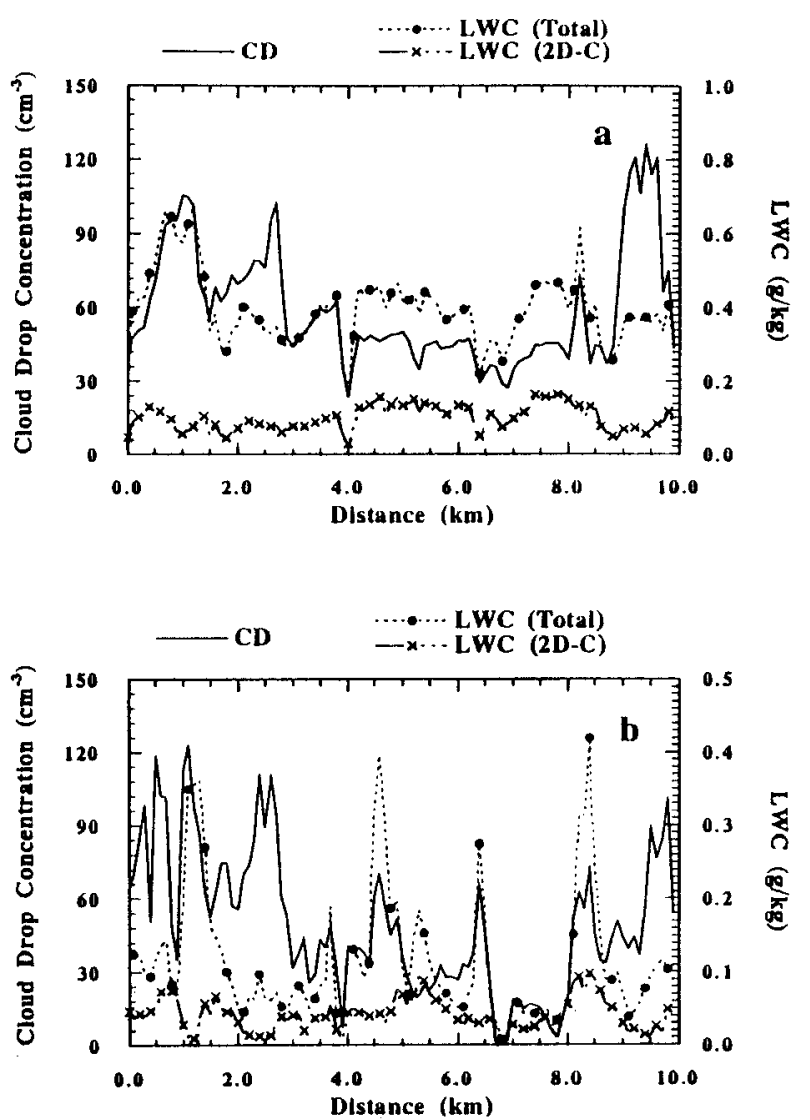

FIG. 18. As for Fig. 16 but for a model simulation of the decoupled case on 29 Jun 1994.

Figure 17 illustrates the effect of the ship track on cloud microstructure by displaying the cloud drop spectra in the $z-x$ cross section for the clean air simulation. The domain from 5.0 to about $7.0 \mathrm{~km}$ covers the region occupied by the ship track, while the rest of the plot (from 7.0 to $9.0 \mathrm{~km}$ ) depicts the ambient cloud. The ship track drop spectra are relatively narrow and are composed mostly of small drops, whereas the drop spectra outside the ship track clearly show bimodal distributions with the second mode corresponding to the drizzle drops.

The effect of the boundary layer structure on drizzle has been investigated in a separate simulation using the sounding obtained by the UKMO C-130 flight on 29 June 1994 at the time the Hanjin Barcelona ship track was observed. In this case, the boundary layer was decoupled and divided into two parts separated by a stable transition layer near $0.4 \mathrm{~km}$. The boundary layer height in this case was about $800 \mathrm{~m}$ and the cloud was about $400 \mathrm{~m}$ thick.

Figure 18 shows model simulations of the variations across the ship track of the drop concentration, the total LWC, and the drizzle LWC for the Hanjin Barcelona case. The ship track at the indicated time of boundary layer evolution is located in the regions from 0 to $3 \mathrm{~km}$ and from 9 to $10 \mathrm{~km}$ (note that separation of the ship track is due to the periodical lateral boundary conditions). The horizontal inhomogeneity and the effect of buoyant updrafts and downdrafts resulted in the significant variation of the ship track parameters on the microscale. The ship track in this case shows significant drizzle both at cloud top (Fig. 18a), as well as cloud base (Fig. 18b). The reduction of drizzle in the ship track compared to the ambient cloud is rather insignificant. The drop spectra shown in Fig. 19 display the portion of the domain that covers the transition from the ship track region (from 1 to $3 \mathrm{~km}$ ) to the unaffected ambient cloud region (from 3 to $5 \mathrm{~km}$ ). In contrast with the Fig. 17, there is no significant difference in the drop spectra between the ship track and ambient cloud. The bimodal spectra, as well as drizzle drops below the cloud base, can be seen in both regions. The more detailed analysis, presented by Liu et al. (2000), reveals that the ship track in the decoupled case is formed by the more buoyant ship track plumes, which can transport the moister surface air and thus increase the total water content in the ship track. This decreases the LWC and enhances drop collisions and drizzle production.

Both of the above modeling studies predict that drizzle will decrease in ship tracks because the cloud droplets are smaller and therefore collide less efficiently. They also predict that decreased drizzle will allow cloud water to increase under clean ambient conditions. Additionally, the models predict that cloud water will be depressed in the lower regions of ship tracks because the supply of liquid water due to drizzle from higher regions in the cloud will be suppressed. This effect will be less noticeable in more polluted ambient clouds with small or no drizzle at all. In a boundary layer, where the cloud layer is strongly decoupled from the surface mixed layer and drizzle plays a significant role in the vertical transport of liquid water (as turbulent transport is reduced), the $1 \mathrm{D}$ model predicts that cloud water will be reduced throughout most of the depth of the ship track. However, the 3D model predicts that cloud water will be increased in ship tracks that form in weakly decoupled boundary layers due to the buoyancy of the ship plume, which produces an increase in the upward transport of moist air from the surface and thus increase in the total water content in the ship track. The model simulations suggest that the effect of ship effluents on drizzle depends on many boundary layer parameters, in particular, on the aerosol loading in the ambient air, as well as on the mean structure and stability of the boundary layer. A combination of these, and probably other, parameters may explain the various observational results concerning drizzle suppression in ship tracks presented in this paper.

\section{Summary}

Although drizzle was a relatively infrequent occurrence in the MAST study, the diverse types of mea- 


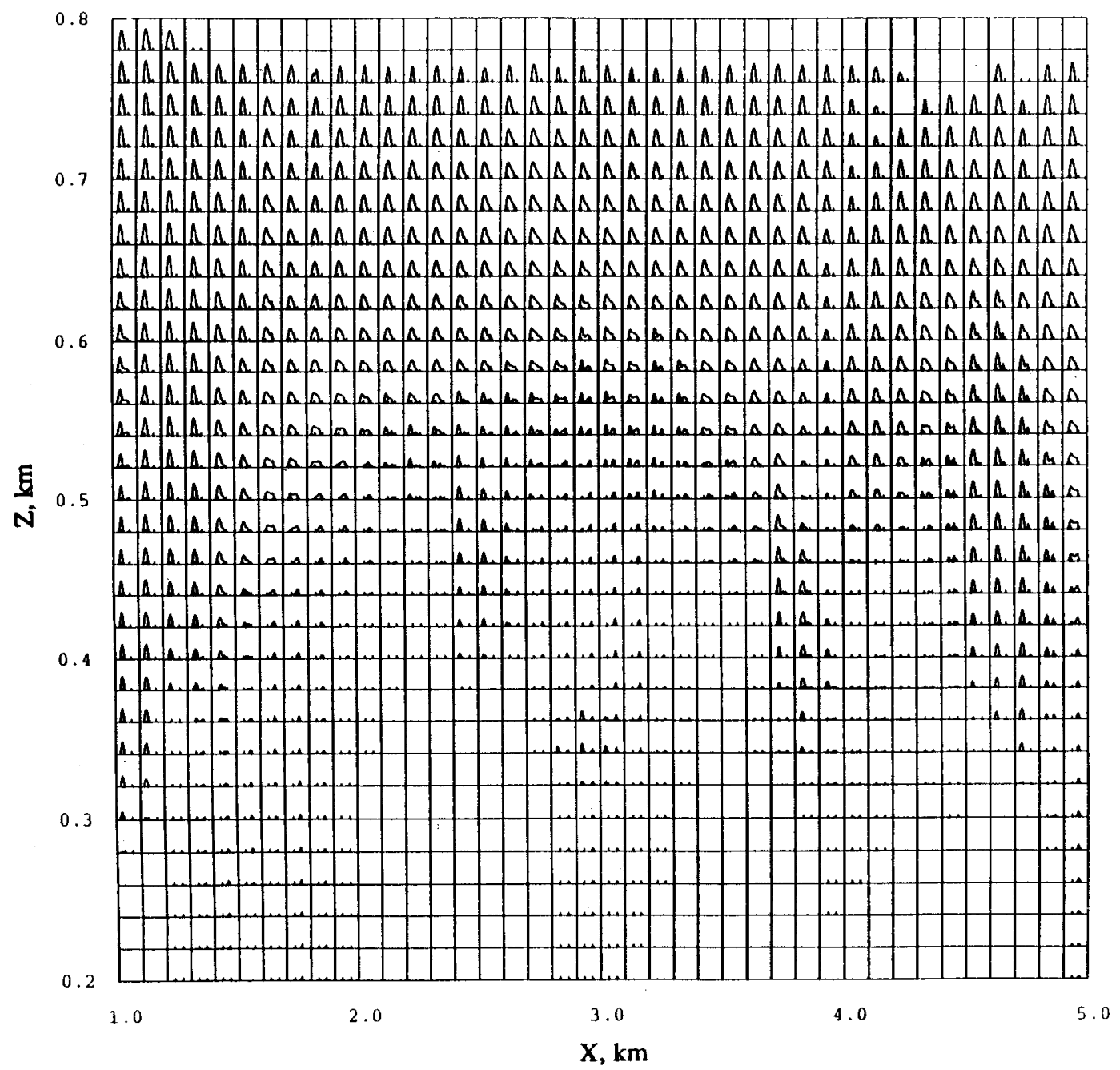

FIG. 19. As for Fig. 17 but for a model simulation of the decoupled case on 29 Jun.

surement devices employed produced signals consistent with a reduction in the drizzle-size drops in clouds affected by ship effluents. In situ microphysical measurements generally showed an increase in the number concentration, and a decrease in the size, of cloud droplets in ship tracks. An increase in liquid water content in the cloud droplet size range was not always observed in ship tracks, primarily because of the relatively small (or often negligible) amounts of water available in the drizzle mode. Significant changes in the droplet size distributions, as well as reductions in the drizzle flux and concentrations of drops $>50-\mu \mathrm{m}$ radius, were observed in regions where drizzle was more uniformly present. In one case (Evergreen Evergenius) a ship plume was released into a more heavily drizzling cloud layer, and the aerosols downwind of the ship showed evidence of being washed out by the drizzle. This limited the effect that aerosols had on suppressing drizzle and may have important consequences for the lifetime of the cloud track.
Aircraft measurements in the ship tracks produced by seven different ships on six different days, when measurable drizzle was present in ambient clouds, indicate that natural variations in liquid water content generally mask any redistribution of water from drizzle-sized drops to the smaller cloud droplets. The effect of redistributing the liquid water in drizzle drops to smallersized droplets may be masked by lack of sensitivity in the measurements over the $25-75-\mu \mathrm{m}$-radius range (i.e., the region between the upper range of the FSSP and the lower range of the PMS 2D probes). Alternatively, as one of the model simulations predicts, an increase in LWC may not be observable because suppression of drizzle reduces the supply of liquid water due to drizzle falling from higher in the cloud.

Radiometric measurements showed that increased droplet concentrations in ship tracks, which resulted in reduced droplet sizes, can significantly alter the cloud liquid water path. Radar observations indicate that the reduced reflectivity in a ship track compared with the 
ambient cloud may be due to a reduction in the concentrations of larger droplets, a reduction in the size of the droplets, or both.

These various lines of evidence, together with numerical model results, support the hypothesis that under some conditions drizzle can be suppressed in ship tracks.

Acknowledgments. We thank the crews of the UW C-131A and the UKMO C-130 for collecting the field data. We thank S. English for providing MARSS data. This work was supported by the Department of the Navy, Office of Naval Research, under Grant N0001492-J-1587.

\section{REFERENCES}

Ackerman, A. S., O. B. Toon, and P. V. Hobbs, 1993: Dissipation of marine stratiform clouds and the collapse of the marine boundary layer due to depletion of cloud condensation nuclei by clouds. Science, 262, 226-229.

$\longrightarrow$, - $\longrightarrow$, and $-1995 \mathrm{a}$ : A model for particle microphysics, turbulent mixing, and radiative transfer in the stratocumulustopped marine boundary layer and comparisons with observations. J. Atmos. Sci., 52, 1204-1236.

- - - and $-1995 \mathrm{~b}$ : Numerical modeling of ship tracks produced by injections of cloud condensation nuclei into marine stratiform clouds. J. Geophys. Res., 100, 7121-7133.

Albrecht, B. A., 1989: Aerosols, cloud microphysics and fractional cloudiness. Science, 245, 1227-1230.

—, C. W. Fairall, D. W. Thomson, A. B. White, J. B. Snider, and W. H. Schubert, 1990: Surface-based remote sensing of the observed and the adiabatic liquid water content of stratocumulus clouds. Geophys. Res. Lett., 17, 89-92.

Baumgardner, D., 1982: A description of FSSP auxiliary variables and their use. NCAR Tech. Note 199, $103 \mathrm{pp}$.

_ 1987: Corrections for the response times of particle measuring probes. Extended Abstracts, Sixth Symp. on Meteorological Observations and Instrumentation, New Orleans, LA, Amer. Meteor. Soc., 148-151.

Brown, P. R. A., 1993: Measurements of the ice water content in cirrus using an evaporative technique. J. Atmos. Oceanic Technol., 10, 579-590.

Clothiaux, E. E., M. A. Miller, B. A. Albrecht, T. P. Ackerman, J. Verlinde, D. M. Babb, R. M. Peters, and W. J. Syrett, 1995: An evaluation of a $94-\mathrm{GHz}$ radar for remote sensing of cloud properties. J. Atmos. Oceanic Technol., 12, 201-229.

Demme, G. J., 1996: Two case studies of diurnal variations in marine stratocumulus clouds. M.S. thesis, Dept. of Meteorology, The Pennsylvania State University, $52 \mathrm{pp}$.

Durkee, P. A., and Coauthors, 2000: The impact of ship-produced aerosols on the microstructure and albedo of warm marine stratocumulus clouds: A test of MAST hypothesis 1i and 1ii. $J$. Atmos. Sci., 57, 2554-2569.

Eagan, R. C., P. V. Hobbs, and L. F. Radke, 1974a: Measurements of cloud condensation nuclei and cloud droplet size distributions in the vicinity of forest fires. J. Appl. Meteor., 13, 553-557.

,-- , and $-1974 \mathrm{~b}$ : Particle emissions from a large kraft paper mill and their effects on the microstructure of warm clouds. J. Appl. Meteor., 13, 535-552.

English, S. J., 1995: Airborne radiometric observations of cloud liquid-water emission at 89 and $157 \mathrm{GHz}$ : Application to retrieval of liquid-water path. Quart. J. Roy. Meteor. Soc., 121, 15011524

Ferek, R. J., D. A. Hegg, P. V. Hobbs, P. A. Durkee, and K. Nielsen, 1998: Measurements of ship-induced tracks in clouds off the Washington coast. J. Geophys. Res., 103, 23 199-23 206.
Gerber, H., 1996: Microphysics of marine stratocumulus clouds with two drizzle modes. J. Atmos. Sci., 53, 1649-1662.

— B. B. Arends, and A. S. Ackerman, 1994: New microphysics sensor for aircraft use. Atmos. Res., 31, 235-252.

Han, Q., W. Rossow, R. Welch, A. White, and J. Chou, 1995: Validation of satellite retrievals of cloud microphysics and liquid water path using observations from FIRE. J. Atmos. Sci., 52, $4183-4195$.

Han, Y., and D. W. Thomson, 1994: Multichannel microwave radiometric observations at Saipan during the 1990 tropical cyclone motion experiment. J. Atmos. Oceanic Technol., 11, 110-121.

Hindman, E. E., P. V. Hobbs, and L. F. Radke, 1977a: Cloud condensation nuclei from a paper mill. Part I: Measured effects on clouds. J. Appl. Meteor., 16, 745-752.

- , P. M. Tag, B. A. Silverman, and P. V. Hobbs, 1977b: Cloud condensation nuclei from a paper mill. Part II: Calculated effects on rainfall. J. Appl. Meteor., 16, 753-755.

Hobbs, P. V., L. F. Radke, and S. E. Shumway, 1970: Cloud condensation nuclei from industrial sources and their apparent influence on precipitation in Washington State. J. Atmos. Sci., 27, 81-89. , —, J. H. Lyons, R. J. Ferek, D. J. Coffman, and T. J. Casadevall, 1991: Airborne measurements of particle and gas emissions from the 1990 volcanic eruptions of Mt. Redoubt. J. Geophys. Res., 96, $18735-18752$.

— their effects on clouds. J. Atmos. Sci., 57, 2570-2590.

Khairoutdinov, M. F., and Y. L. Kogan, 1999: A large eddy simulation model with explicit microphysics: Validation against aircraft observations of a stratocumulus-topped boundary layer. J. Atmos. Sci., 56, 2115-2131.

Kilsby, C. G., D. P. Edwards, R. W. Saunders, and J. S. Foot, 1992: Water-vapor continuum absorption in the tropics: Aircraft measurements and model comparisons. Quart. J. Roy. Meteor. Soc., 118, 715-748.

King, M. D., L. F. Radke, and P. V. Hobbs, 1993: Optical properties of marine stratocumulus clouds modified by ships. J. Geophys. Res., 98, 2729-2739.

Kogan, Y. L., 1991: The simulation of a convective cloud in a 3-D model with explicit microphysics. Part I: Model description and sensitivity experiments. J. Atmos. Sci., 48, 1160-1189.

—, M. P. Khairoutdinov, D. K. Lilly, Z. N. Kogan, and Q. Liu, 1995: Modeling of stratocumulus cloud layers in a large eddy simulation model with explicit microphysics. J. Atmos. Sci., 52, 2923-2940.

Liu, Q., Y. L. Kogan, D. K. Lilly, D. W. Johnson, G. E. Innis, P. A. Durkee, and K. E. Nielsen, 2000: Modeling of ship effluent transport and its sensitivity to boundary layer structure. J. Atmos. Sci., 57, 2779-2791.

Martin, G. M., D. W. Johnson, and A. Spice, 1994: The measurement and parameterization of the effective radius of warm stratocumulus clouds. J. Atmos. Sci., 51, 1823-1842.

Mossop, S. C., 1983: Intercomparison of instruments used for measurement of cloud drop concentration and size distribution. $J$. Climate Appl. Meteor., 22, 419-428.

Nicholls, S., 1978: Measurements of turbulence by an instrumented aircraft in a convective atmospheric boundary layer. Quart. $J$. Roy. Meteor. Soc., 104, 653-676.

_ 1984: The dynamics of stratocumulus: Aircraft observations and comparisons with a mixed layer model. Quart. J. Roy. Meteor. Soc., 110, 1141-1170.

— of stratiform cloud sheets. Quart. J. Roy. Meteor. Soc., 112, 431460.

Penc, R. S., and B. A. Albrecht, 1987: Parametric representation of heat and moisture fluxes in cloud-topped mixed layers. Bound.Layer Meteor., 38, 225-248.

Radke, L. F., J. A. Coakley Jr., and M. D. King, 1989: Direct and remote sensing observations of the effects of ships on clouds. Science, 246, 1146-1149. 
Rawlins, F., and J. S. Foot, 1990: Remotely sensed measurements of stratocumulus properties during FIRE using the C130 aircraft multichannel radiometer. J. Atmos. Sci., 47, 2488-2503.

Russell, L. M., K. J. Noone, R. J. Ferek, R. A. Pockalny, R. C. Flagan, J. H. Seinfeld, 2000: Combustion organic aerosol as cloud condensation nuclei in ship tracks. J. Atmos. Sci., 57, 2591-2606.

Saunders, R. W., G. Brogniez, J. C. Buriez, R. Meerkötter, and P. Wendling, 1992: A comparison of measured and modeled broadband fluxes from aircraft data during the ICE ' 89 field experiment. J. Atmos. Oceanic Technol., 9, 391-406.

Squires, P., 1958: The microstructure and colloidal stability of warm clouds. Tellus, 10, 256-271.

Taylor, J. P., 1992: Sensitivity of remotely sensed effective radius of cloud droplets to changes in LOWTRAN version. J. Atmos. Sci., 49, 2564-2569.

, M. D. Glew, J. A. Coakley Jr., W. R. Tahnk, S. Platnick, P. V.
Hobbs, and R. J. Ferek, 2000: Effects of aerosols on the radiative properties of clouds. J. Atmos. Sci., 57, 2656-2670.

Tremback, C. J., J. Powell, W. R. Cotton, and R. A. Pielke, 1987:

The forward-in-time upstream advection scheme: Extension to higher orders. Mon. Wea. Rev., 115, 540-555.

Wallace, J. M., and P. V. Hobbs, 1977: Atmospheric Science: An Introductory Survey. Academic Press, $467 \mathrm{pp}$.

Warner, J., 1968: A reduction in rainfall associated with smoke from sugarcane fires-An inadvertent weather modification? J. Appl. Meteor., 7, 247-251.

- , and S. Twomey, 1967: The production of cloud nuclei by cane fires and their effect on cloud droplet concentration. J. Atmos. Sci., 24, 704-706.

Wyant, M. C., C. S. Bretherton, H. A. Rand, and D. E. Stevens, 1997: Numerical simulations and a conceptual model of the stratocumulus to trade cumulus transition. J. Atmos. Sci., 54, 168-192. 